\title{
Article \\ Genome-Wide Analysis of Potassium Channel Genes in Rice: Expression of the OsAKT and OsKAT Genes under Salt Stress
}

\author{
Zahra Musavizadeh ${ }^{1}$, Hamid Najafi-Zarrini ${ }^{2}$, Seyed Kamal Kazemitabar ${ }^{2}$, Seyed Hamidreza Hashemi ${ }^{3}{ }^{(0)}$, \\ Sahar Faraji ${ }^{2}$, Gianni Barcaccia ${ }^{4}(\mathbb{D})$ and Parviz Heidari ${ }^{5, *}$ \\ 1 Department of Biochemical Sciences, Sapienza University of Rome, 00185 Rome, Italy; \\ Zahra.musavizadeh@uniroma1.it \\ 2 Department of Plant Breeding, Sari Agricultural Sciences and Natural Resources University (SANRU), \\ Sari 4818166996, Iran; najafi316@yahoo.com (H.N.-Z.); kazemi_ka@yahoo.com (S.K.K.); \\ sahar.faraji@rocketmail.com (S.F.) \\ 3 Genetics and Agricultural Biotechnology Institute of Tabarestan, Sari Agricultural Sciences and Natural \\ Resources University, Sari 4818166996, Iran; irahamidreza@yahoo.com \\ 4 Laboratory of Genomics for Breeding, DAFNAE, Campus of Agripolis, University of Padova, Legnaro, \\ 35020 Padova, Italy; gianni.barcaccia@unipd.it \\ 5 Faculty of Agriculture, Shahrood University of Technology, Shahrood 3619995161, Iran \\ * Correspondence: heidarip@shahroodut.ac.ir; Tel.: +98-912-0734-034
}

check for

updates

Citation: Musavizadeh, Z.;

Najafi-Zarrini, H.; Kazemitabar, S.K.;

Hashemi, S.H.; Faraji, S.; Barcaccia, G.;

Heidari, P. Genome-Wide Analysis of

Potassium Channel Genes in Rice:

Expression of the OsAKT and OsKAT

Genes under Salt Stress. Genes 2021

12, 784. https://doi.org/10.3390/

genes12050784

Academic Editor: Joohyun Lee

Received: 17 April 2021

Accepted: 18 May 2021

Published: 20 May 2021

Publisher's Note: MDPI stays neutral with regard to jurisdictional claims in published maps and institutional affiliations.

Copyright: (c) 2021 by the authors. Licensee MDPI, Basel, Switzerland. This article is an open access article distributed under the terms and conditions of the Creative Commons Attribution (CC BY) license (https:/ / creativecommons.org/licenses/by/ $4.0 /)$.

\begin{abstract}
Potassium $(\mathrm{K}+)$, as a vital element, is involved in regulating important cellular processes such as enzyme activity, cell turgor, and nutrient movement in plant cells, which affects plant growth and production. Potassium channels are involved in the transport and release of potassium in plant cells. In the current study, three OsKAT genes and two OsAKT genes, along with 11 nonredundant putative potassium channel genes in the rice genome, were characterized based on their physiochemical properties, protein structure, evolution, duplication, in silico gene expression, and protein-protein interactions. In addition, the expression patterns of OsAKTs and OsKATs were studied in root and shoot tissues under salt stress using real-time PCR in three rice cultivars. $K+$ channel genes were found to have diverse functions and structures, and OsKATs showed high genetic divergence from other $K+$ channel genes. Furthermore, the Ka/Ks ratios of duplicated gene pairs from the K+ channel gene family in rice suggested that these genes underwent purifying selection. Among the studied $\mathrm{K}+$ channel proteins, OsKAT1 and OsAKT1 were identified as proteins with high potential N-glycosylation and phosphorylation sites, and LEU, VAL, SER, PRO, HIS, GLY, LYS, TYR, CYC, and ARG amino acids were predicted as the binding residues in the ligand-binding sites of $\mathrm{K}+$ channel proteins. Regarding the coexpression network and KEGG ontology results, several metabolic pathways, including sugar metabolism, purine metabolism, carbon metabolism, glycerophospholipid metabolism, monoterpenoid biosynthesis, and folate biosynthesis, were recognized in the coexpression network of $\mathrm{K}+$ channel proteins. Based on the available RNA-seq data, the $K+$ channel genes showed differential expression levels in rice tissues in response to biotic and abiotic stresses. In addition, the real-time PCR results revealed that OsAKTs and OsKATs are induced by salt stress in root and shoot tissues of rice cultivars, and OsKAT1 was identified as a key gene involved in the rice response to salt stress. In the present study, we found that the repression of OsAKTs, OsKAT2, and OsKAT2 in roots was related to salinity tolerance in rice. Our findings provide valuable insights for further structural and functional assays of $K+$ channel genes in rice.
\end{abstract}

Keywords: in silico study; potassium transporters; protein-protein interaction; comparative genomics; posttranslational modifications; gene expression

\section{Introduction}

Potassium $(\mathrm{K}+)$, as a fundamental macronutrient, is essential for plant growth and plays an important role in regulating cellular processes such as the control of $\mathrm{pH}$ and cell 
turgor [1,2]. Potassium is also involved in regulating the activity of many enzymes as an essential cofactor [3,4]. In addition, $\mathrm{K}+$ is required for the transport of phloem solute and maintaining the balance of cations:anions in the cytosol and the vacuole [5]. Furthermore, potassium plays a vital role in plant adaptation to abiotic stresses, including salinity and drought $[6,7]$, and biotic stresses, including pathogen attack and the resulting wounds [8,9]. Changing the concentration of potassium in plant tissues and cells effectively regulates the response of plants to environmental changes [4]. For example, to counteract the harmful effects of other ions, the potassium concentration in the cytoplasm is in the range of $100-200 \mathrm{mM}$ and is not replaced by other cations, while the potassium concentration in the vacuoles is variable and can be replaced by other osmotica $[10,11]$. This replacement is effective in maintaining cellular pressure. Potassium is transported by various systems in plant cells. $\mathrm{K}+$ channels are involved in the transport and release of potassium [1,12]. $\mathrm{K}+$ channels are grouped into different categories according to the type of activity, influx, and efflux $[2,13] . \mathrm{K}+$ channels are found in cell membranes, vacuolar membranes, xylem, and phloem tissues that participate in maintaining homeostasis and the transport of potassium within the plant cell $[1,12,13] . \mathrm{K}+$ channels are involved in $\mathrm{K}+$ loading in xylem and phloem, as well as accumulation in vacuoles [13]. A broad range of genes encoding $K+$ channels have expanded during evolution and obtained specific functions in plants [12]. Many $\mathrm{K}+$ channel proteins linked to the uptake and release of $\mathrm{K}+$ from the cell have been stated in different plant species $[2,14,15]$.

$\mathrm{K}+$ channels are divided into two main categories, including voltage-gated $\mathrm{K}+$ channels and voltage-independent $\mathrm{K}+$ channels, based on their mechanisms $[3,16]$. In plants, four subgroups of voltage-gated plant $\mathrm{K}+$ channels have been segregated, including Outward-rectifying $\mathrm{K}+\left(\mathrm{K}_{\text {out }}\right)$ channels, Inward-rectifying $\mathrm{K}+\left(\mathrm{K}_{\text {in }}\right)$ channels, Weak-rectifying $\mathrm{K}+\left(\mathrm{K}_{\text {weak }}\right)$ channels, and Silent-rectifying $\mathrm{K}+\left(\mathrm{K}_{\text {silent }}\right)$ [17]. Besides, various $K+$ channel genes have been identified and characterized in plant species. For instance, in Arabidopsis, KAT1 and AKT1 were identified as inward-rectifying shaker-like $\mathrm{K}+$ channels $\left(\mathrm{K}_{\text {in }}\right)$, in which KAT1 is involved in the transfer of potassium in guard cells [18-20]. AKT1, a significant factor in the uptake of $\mathrm{K}+$, is highly expressed in root epidermal cells $[16,21,22]$, while $A K T 2$ is identified as a weak-rectifying $\left(\mathrm{K}_{\text {weak }}\right)$ channel [3]. Furthermore, the Guard cell Outward-Rectifying $\mathrm{K}+(\mathrm{GORK})$ channel, as a $\mathrm{K}+$ efflux channel $\left(\mathrm{K}_{\text {out }}\right)$ in guard cells, induces stomatal closure [23,24]. The rice genome contains three OsKAT genes, OsKAT1, OsKAT2, and OsKAT3, which encode inward rectifying shaker-like potassium channels, and two OsAKTs (OsAKT1 and OsAKT2) [25,26]. Moon et al. found that OsKAT2, a rice-KAT gene, is mainly expressed in guard cells involved in stomatal opening and was introduced as part of the response to drought stress [25]. It has also been stated that the OsKAT1 gene increases salinity tolerance in rice [26]. One of the critical aspects of the effect of potassium in plant cells is the interaction of this element with sodium $(\mathrm{Na}+)$, which is useful in increasing plant tolerance to salinity stress [27]. The activity of $\mathrm{K}+$ channels is affected by salinity. For instance, OsAKT1 transcription is downregulated in response to salt stress [28], while the expression levels of $A K T 2 / 3$, as a gene localized in the phloem, are upregulated by salinity [29]. AKT2/3 is probably involved in controlling $\mathrm{K}+$ homeostasis in plants and the $\mathrm{K}+/ \mathrm{Na}+$ ratio by controlling the recirculation of $\mathrm{K}+$ in the phloem [30]. It has also been stated that posttranslational modifications such as phosphorylation can affect the AKT1 protein and increase the channel activity of AKT1 [21,31].

A comprehensive genomic study of potassium channel proteins can reveal valuable information on the sequence structure and interaction between these proteins. To date, studies have been conducted on the function of these genes in different plants, but many regulatory and structural aspects of these proteins are still unknown. In the current study, potassium channel proteins, especially OsAKTs and OsKATs, were compared based on their sequence structure, physicochemical properties, protein interaction network, posttranslational modifications, and expression profile in rice. Overall, the reported results in the present study will enhance our knowledge about the evolution and function of 
OsAKTs and OsKATs and can serve as a basis for revealing the regulatory mechanism and functional genomic analysis of $A K T$ and $K A T$ genes.

\section{Materials and Methods}

\subsection{Identification of Potassium Channel Proteins in Rice}

The HMM profile related to the $\mathrm{K}+$ channel protein domains (PF07885, PF00520, PF11834) was first retrieved through the Pfam database [32], and an HMM search (HMMER3.0) was conducted to detect the putative $\mathrm{K}+$ channel proteins in the rice genome (Oryza sativa Japonica Group cv. Nipponbare), with an expected value of $\mathrm{E}^{-10}$. The recognized nonredundant putative $\mathrm{K}+$ channel proteins were manually checked for specific domains by employing the Pfam and SMART [33] programs. The corresponding cDNA and genomic sequences of the identified proteins, as well as the chromosomal location of $K+$ channel genes, were obtained from the EnsemblPlants database [34]. The physicochemical properties of $\mathrm{K}+$ channel proteins, such as molecular weights and isoelectric points ( $\mathrm{pIs}$ ), were identified through the ProtParam program [35].

\subsection{Phylogenetic Relationships, Conserved Protein Motifs, and Gene Structures}

$\mathrm{K}+$ channels protein sequences from rice were used as the queries, to identify their orthologous in Arabidopsis thaliana, Brachypodium distachyon, Zea mays, and Sorghum bicolor using the BLAST tool of the EnsemblPlants database. The phylogenetic relationships were investigated by constructing a neighbor-joining phylogenetic tree via MEGAX software [36] according to the protein sequences of $\mathrm{K}+$ channels from rice, $A$. thaliana, B. distachyon, $\mathrm{Z}$. mays, and S. bicolor with 1000 bootstrap replicates. The MEME (Multiple Em for Motif Elicitation) server was also employed to discover the conserved protein motifs in $\mathrm{K}+$ channel proteins [37]. The exon/intron organizations in the genes were predicted through the Gene Structure Display Server [38].

\subsection{Chromosomal Mapping, Gene Duplications, and Estimation of the Ka/Ks Ratio}

The K+ channel genes were mapped onto the rice chromosomes using MapChart software [39]. The duplication events were identified by alignment of the coding DNA sequences of K+ channel genes via CLUSTALW [40], and then the matrix was imported into BioEdit software (v. 7.2.5) [41]. Gene duplication was determined as genes sharing more than $80 \%$ identity in their nucleotide sequences. The synonymous (Ks) and nonsynonymous (Ka) rates per site among the duplicated pairs were calculated using DnaSP v6 software [42]. The time of division of duplicated pairs was estimated using a synonymous mutation rate of $\lambda$ substitutions per synonymous site per year, as $\mathrm{T}=\left(\mathrm{Ks} / 2 \lambda\left(\lambda=6.5 \times 10^{-9}\right)\right) \times 10^{-6}$ [43] The synteny relationships at both the gene and chromosome levels of $K+$ channel genes in rice with their orthologous pairs in maize, Arabidopsis, B. distachyon, and S. bicolor were visualized by Circos software [44].

\subsection{Coexpression Network of $K+$ Channel Genes}

The co-expression networks related to $K+$ channel genes were constructed using the ATTED-II ver 9.0 server [45] with the coex option on many genes and PPI option on a few genes; finally, the results were visualized with Cytoscape [46]. The genes directly connected with $\mathrm{K}+$ channel proteins in various biological pathways were further investigated based on RNA-seq and KEGG (Kyoto Encyclopedia of Genes and Genomes) data on the gene networks.

\subsection{D Protein Modeling, Validation, and Docking Analysis of the Pocket Sites}

The three-dimensional structures of the $\mathrm{K}+$ channel proteins in rice were predicted through the Protein Homology/analogy Recognition Engine V 2.0 (Phyre2) server [47]. The predicted protein model validation was assessed through Ramachandran plot analysis [48]. Docking analysis of the ligand-binding regions in the predicted protein models was also performed via CASTp [49] and DeepSite [50] tools and finally visualized in PyMOL [51]. 


\subsection{Expression Profiling of K+ Channel Genes Based on RNA-Seq Data}

The available RNA-seq data related to the rice genome were employed for expression assays of $\mathrm{K}+$ channel family members in multiple tissues and during exposure to various biotic and abiotic stimuli. These data contained a wide range of developmental stages of rice, including leaves at 20 days, pre- and postemergence inflorescences, anthers, pistils, seeds, embryos, endosperm, seedlings, calli, and panicles. In addition, the gene expression data under different stresses, including phosphate starvation (Pi), cadmium (Cd), drought (DR), salinity (S), and arsenic (As) stresses, were downloaded from the Rice Expression Database [52] (SRP028766, DRP001141, SRP052306, DRP002329, SRP011893) [53-55]. In addition, the RNA-seq data of rice under mock, blast infection, Xanthomonas oryzae, and bacterial blight disease were downloaded from public data [56,57]. The transcript magnitudes were determined in fragments per kilobase per million mapped reads (FPKM) based on the exon model and then log2 transformed to generate heatmaps via the TBtools package [58].

\subsection{Plant Materials and Stress Treatments}

The seeds of three rice cultivars, IR29, Sang tarom, and Jelodar, were collected from the Mazandaran Province in Iran. The studied cultivars differed in their salinity tolerance rate: Sang tarom was a moderately tolerant cultivar; IR29 was a susceptible cultivar; and Jelodar was a moderately susceptible cultivar. Seeds were sterilized in $0.2 \%(w / v)$ sodium hypochlorite for $1 \mathrm{~min}$ and then placed in petri dishes containing two layers of Whatman filter paper. All petri dishes were incubated at a temperature of $25 \pm 3{ }^{\circ} \mathrm{C}$. After four days, germinated seeds were moved to a Yoshida solution [59] at $\mathrm{pH} 5-5.5$ for further growth. In the present study, we used aerated hydroponic tanks holding $30 \mathrm{~L}$ solution, and 80 seedlings were vertically cultured in each tank. The nutrient solution was exchanged once a week, and the $\mathrm{pH}$ was adjusted every three days. Seedlings were grown at $25 \pm 3{ }^{\circ} \mathrm{C}$, a $16 \mathrm{~h}$ photoperiod, and $60-65 \%$ relative humidity. Three-week-old seedlings were subjected to $120 \mathrm{mM} \mathrm{NaCl}$ treatment. Salt-treated plants were harvested after $6 \mathrm{~h}, 24 \mathrm{~h}, 72 \mathrm{~h}, 120 \mathrm{~h}$, and $168 \mathrm{~h}$ time courses. Nontreated seedlings were also considered the control sample. Collected root and leaf samples were frozen immediately in liquid nitrogen and stored at $-80{ }^{\circ} \mathrm{C}$ until use.

\subsection{RNA Isolation and Quantitative Real-Time PCR Analysis}

Total RNA was extracted using TRIzol reagent (Invitrogen, Carlsbad, CA, USA) according to the manufacturer's instructions. The purified total RNA was checked using agarose gel electrophoresis and a NanoDrop ND 1000 Spectrophotometer (Wilmington, DE, USA). DNase I treatment was performed to eliminate genomic DNA contamination using a ThermoFisher (Thermo Fisher Scientific, Wilmington, MA, USA) DNase Kit according to the manufacturer's instructions. DNase I-treated RNA was used to synthesize first-strand cDNA using the QuantiTect Reverse Transcription Kit (Qiagen, Hilden, Germany) and oligo (dT) primers in a $20 \mu \mathrm{L}$ final volume, according to the manufacturer's instructions. RT-PCR was performed using $3 \mu \mathrm{L}$ RNA, $1 \mu \mathrm{L}$ of specific primers (forward and reverse), $10 \mu \mathrm{M}$ dNTPs, $5 \times$ PCR buffer, and $1 \mu \mathrm{L}$ RiboLock RNase Inhibitor. Finally, PCR was performed, and the products were separated on a $1 \%$ agarose gel to check quality the gene fragments. First-strand cDNA mixtures were utilized as templates for real-time PCR analysis.

The cDNA sequences of the OsAKTs and OsKATs in rice, including OsAKT1 (Os01g0648000), OsAKT2 (Os05g0428700), OSKAT1 (Os02g0245800), OsKAT2 (Os01g0210700), and OsKAT3 (Os01g0756700), were selected for the transcription assay. The gene-specific primers were designed for candidate genes and internal controls using Primer3 online software for candidate genes and internal controls (Table S1). In the present study, the $\beta$-actin gene was used as an internal control for data normalization. Quantitative real-time PCR (qPCR) was performed in a $10 \mu \mathrm{L}$ volume containing $2 \mu \mathrm{L}$ of cDNA, $5 \mu \mathrm{L}$ of $2 \times$ SYBR Green Master Mix, $0.3 \mu \mathrm{L}$ of each $10 \mu \mathrm{M}$ primer, and $2.7 \mu \mathrm{L}$ of RNase-free water. The amplifica- 
tion reactions were carried out in a two-step thermal cycler protocol (Thermo Scientific) according to the company's procedures: a $10 \mathrm{~min}$ initial activation step at $95^{\circ} \mathrm{C}$, followed by 40 cycles of $95^{\circ} \mathrm{C}$ for $15 \mathrm{sec}$ and $60^{\circ} \mathrm{C}$ for $1 \mathrm{~min}$. After 40 cycles, the amplification specificity was checked based on the melting curves by heating the amplicons from 55 to $95^{\circ} \mathrm{C}$. In this study, each treatment of the experiment was repeated in three biological replicates. To increase the reliability of the gene expression analysis, real-time PCR experiments were performed with three identical technical replications. For quantitative real-time PCR data, the relative expression of genes was calculated based on the threshold cycle (CT) method. Accordingly, the relative expression level of the target genes was calculated by the $2^{-\Delta \Delta C T}$ equation [60]. A student's t-test was applied to determine the significant difference ( $p$-value $<0.05$ and $<0.01$ ) between the applied treatments (salt stress at different time courses) and control. In the current study, control samples included conditions without salt stress. All expression results were constructed using Prism 6 software (GraphPad Software Inc., San Diego, CA, USA) based on the mean and standard division (SD) of each gene.

\section{Results}

\subsection{Genome-Wide Characterization of K+ Channel Genes}

In the current study, 16 nonredundant putative $K+$ channel genes in the rice genome were identified and characterized based on their physicochemical properties and sequences (Table 1). The identified genes showed diverse functions in the inward and outward transport of potassium. Furthermore, the $\mathrm{K}+$ channel genes encoded proteins with lengths from 286 (Os04g0117500; as a voltage-dependent K+ channel) to 935 (Os01g0648000; OsAKT1) amino acid residues and with an MW in the range between 33.54 (Os01g0696100; as an outward $\mathrm{K}+$ channel) and $104.46 \mathrm{kDa}$ (Os01g0648000; OsAKT1). In addition, the exon number varied from one (Os06g0254200; NKT5) to 11 (Os01g0648000, Os01g0210700, Os02g0245800, and Os06g0250600), and the $\mathrm{pI}$ ranged from 5.78 (Os06g0250600; as an outward shaker $\mathrm{K}+$ channel) to 10.39 (Os04g0117500).

Table 1. List of studied potassium channel genes in rice.

\begin{tabular}{|c|c|c|c|c|c|c|}
\hline Gene ID & Description & CDS (bp) & Peptide (aa) & Exon No. & MW (kDa) & pI \\
\hline Os01g0648000 & OsAKT1 & 3389 & 935 & 11 & 104.46 & 7.21 \\
\hline Os05g0428700 & OsAKT2, Potassium channel protein ZMK2 & 1858 & 566 & 7 & 78.54 & 6.85 \\
\hline Os02g0245800 & $\begin{array}{l}\text { OsKAT1, Inward facing shaker-like } \\
\text { potassium channel }\end{array}$ & 2343 & 718 & 11 & 82.97 & 7.21 \\
\hline Os01g0210700 & OsKAT2 Potassium channel & 2218 & 568 & 11 & 65.85 & 8.30 \\
\hline Os01g0756700 & OsKAT3, Shaker potassium channel & 1867 & 502 & 9 & 58.01 & 8.32 \\
\hline Os01g0696100 & $\begin{array}{l}\text { Osrok, Putative outwardly facing } \\
\qquad \mathrm{K}+\text { channel }\end{array}$ & 1218 & 405 & 2 & 33.54 & 6.19 \\
\hline Os06g0254200 & Potassium channel protein NKT5 & 1833 & 610 & 1 & 67.39 & 8.98 \\
\hline Os04g0117500 & Potassium channel, voltage-dependent & 1323 & 286 & 7 & 42.79 & 10.39 \\
\hline Os12g0118400 & Inwardly facing potassium channel & 2053 & 529 & 1 & 58.75 & 9.18 \\
\hline Os03g0752300 & TPKA, Two-pore $\mathrm{K}+$ channel family protein & 1672 & 347 & 3 & 39.24 & 8.16 \\
\hline Os04g0445000 & $\begin{array}{l}\text { Potassium channel SKOR (Stelar K(+) } \\
\text { outward facing channel) }\end{array}$ & 1646 & 454 & 8 & 81.82 & 8.48 \\
\hline Os07g0108800 & TPKB, Two-pore K+ channel family protein & 1468 & 349 & 1 & 37.91 & 6.26 \\
\hline Os02g0817500 & $\begin{array}{l}\text { KOB1, Potassium channel, } \\
\text { voltage-dependent, } \beta \text { subunit }\end{array}$ & 1326 & 328 & 4 & 36.45 & 7.49 \\
\hline Os09g0299400 & TPK1, Two pore potassium channel c & 1513 & 456 & 2 & 49.66 & 9.24 \\
\hline Os06g0250600 & $\begin{array}{l}\text { OsK5.2, KOR1, Outward facing shaker K+ } \\
\text { channel, K+ release by guard cells }\end{array}$ & 3025 & 858 & 11 & 97.38 & 5.78 \\
\hline Os01g0718700 & Potassium channel protein & 1311 & 373 & 7 & 66.84 & 9.08 \\
\hline
\end{tabular}


According to the gene structure and conserved motif distribution, the $K+$ channel genes showed diverse sequence structures (Figure 1, panel A). In the present study, 15 conserved motifs were detected in $\mathrm{K}+$ channel proteins, and motif 1 was observed in most proteins (Table S2). Three OsKAT proteins and two OsAKT proteins showed a similar motif distribution pattern (Figure 1, panel B). In addition, $K+$ channel genes were diverse in terms of gene structure, where various intron/exon numbers were observed (Figure 1, panel C).

A

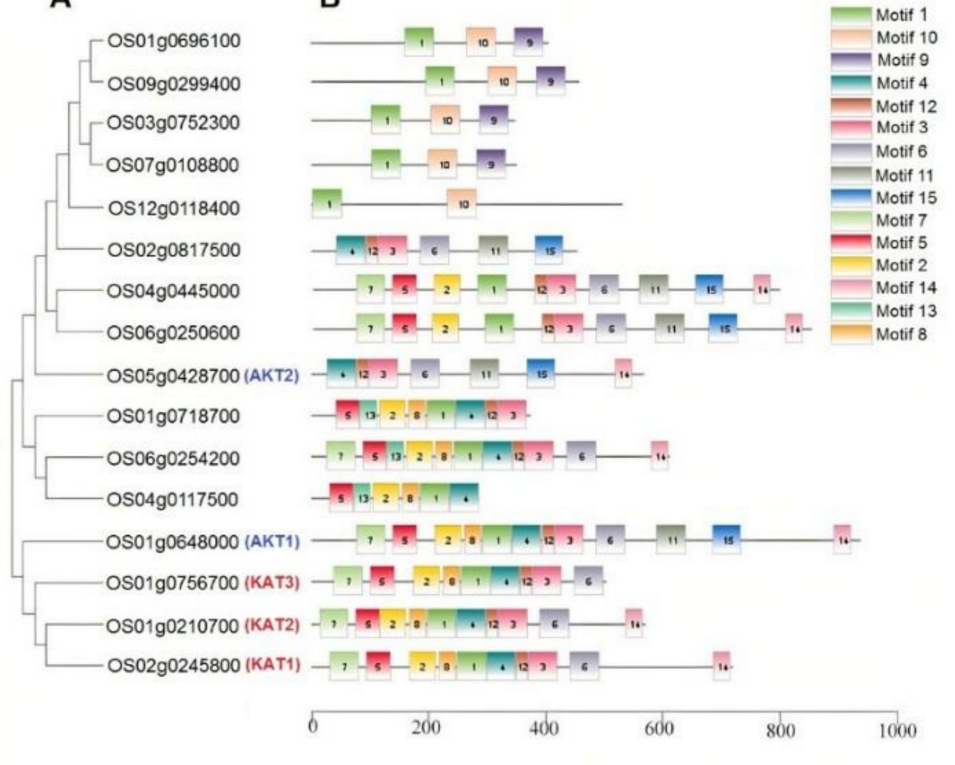

C

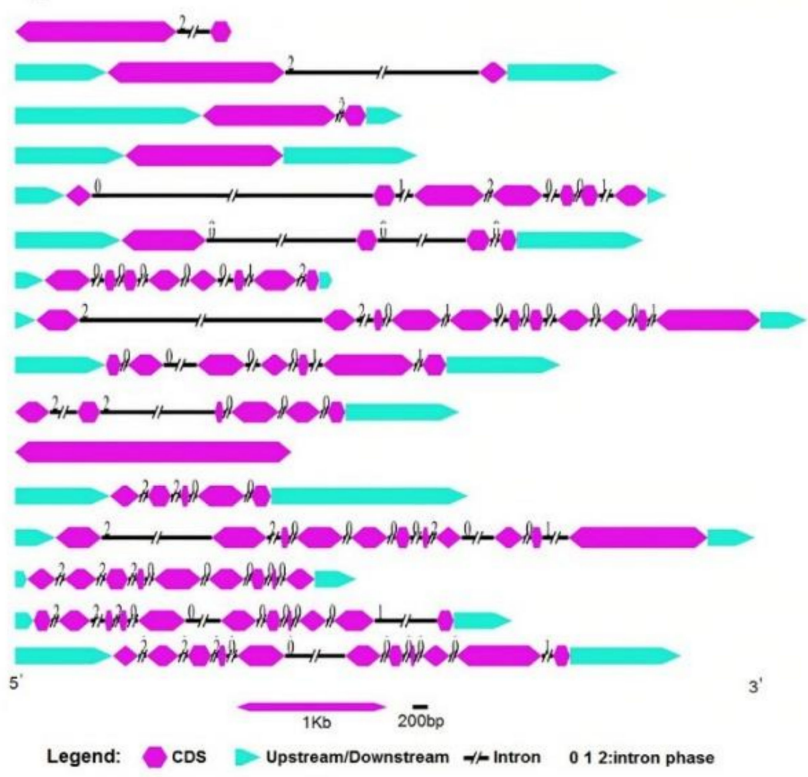

Figure 1. Phylogenetic analyses of the motifs in proteins and gene structures of $K+$ channel genes in rice. Phylogeny of $\mathrm{K}+$ channel proteins (A), conserved motif distribution of $\mathrm{K}+$ channel proteins (B), and intron-exon distribution of $K+$ channel genes (C).

\subsection{Phylogenetic Analysis}

In the present study, the evolutionary relationships of $16 \mathrm{~K}+$ channel proteins in rice with their orthologs in A. thaliana, B. distachyon, Z. mays, and S. bicolor revealed that $\mathrm{K}+$ channel proteins could be divided into six groups (Figure 2). Group I, with $25 \mathrm{~K}+$ channel proteins, was found to be the largest clade. Groups II, III, IV, V, and VI included 8, 10, 9,7 , and $6 \mathrm{~K}+$ channel proteins, respectively. In addition, the members of group VI that contained the OsKATs showed high genetic divergence from other $\mathrm{K}+$ channel proteins. The phylogenetic results illustrated that the $\mathrm{K}+$ channel proteins of rice were most similar to their orthologous genes in maize. Moreover, OsKAT3 (Os01g0756700) showed the greatest genetic divergence from other orthologous genes.

\subsection{Genomic Distribution and Duplication Assay of K+ Channel Family Genes}

The $K+$ channel genes were mapped onto 9 out of 12 chromosomes in the rice genome. The chromosomal map illustrated an unequal distribution of the gene family members throughout the chromosomes (Figure 3). Chromosome 1 contained the largest number of $K+$ channel genes with five genes, while only one $K+$ channel gene was localized on chromosomes $3,5,7,9$, and 12 . It was reported that many $K+$ channel genes in some plant species might be generated through gene duplication events, revealing a paleopolyploid origin for these important nutritional crops. Five segmental-duplicated gene pairs, categorized into three groups (including duplication and triplication events), were recognized in the $K+$ channel gene family. Each group has been denoted by different colors, revealing paralogous pairs (Figure 3). The highest numbers of duplicated/triplicated genes were distributed on chromosome 1, with three duplicated genes clustered into the various gene groups (Table S3). The intraspecies synteny results showed that some of the duplicated 
blocks were collinear, such as Os01g0210700, Os01g0718700, and Os01g0756700 (Figure S1). $\mathrm{The} \mathrm{Ka} / \mathrm{Ks}$ magnitudes related to the paralogous pairs covered a domain from 0.105 to 0.236 , and according to these ratios, duplication events were estimated to occur between approximately 84 and 204 million years ago (MYA) (Table S3). In addition, the Ka/Ks ratios were less than 1 in duplicated gene pairs from the $K+$ channel gene family in rice. This suggests that these genes have undergone purifying selection after duplication $[61,62]$.

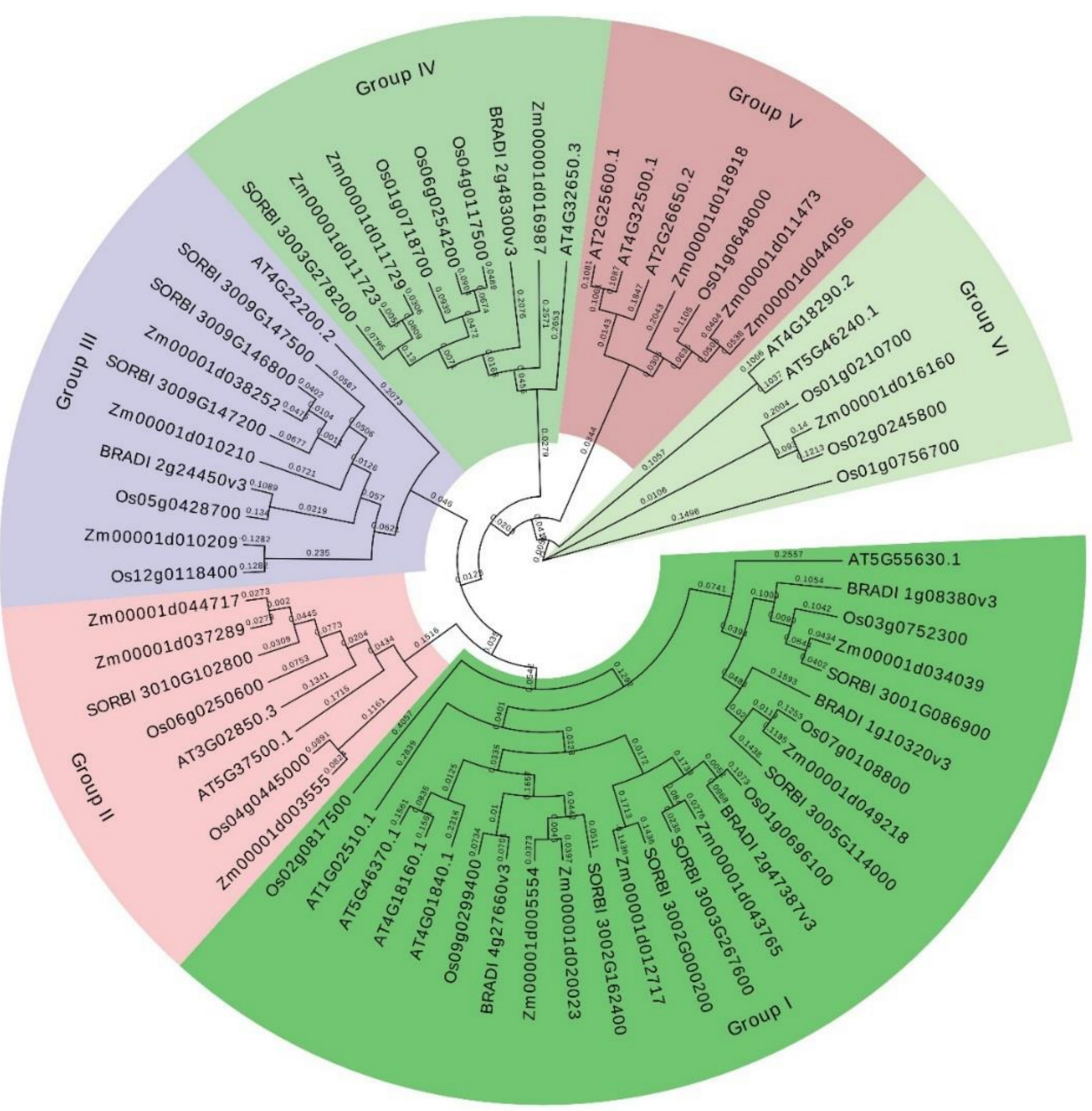

Figure 2. The phylogenetic tree of $\mathrm{K}+$ channel proteins from rice along with protein sequences from four other species. The start of each gene ID contains the code for the species as Os: O. sativa; Zm: Z. mays; AT: A. thaliana; BRADI: B. distachyon; and SORBI: S. bicolor.

\subsection{Conserved Synteny Relationships of K+ Channel Genes}

To further study the evolutionary processes of $K+$ channel genes, the synteny analysis was performed between $K+$ channel genes from rice and their orthologs in A. thaliana, $B$. distachyon, S. bicolor, and Z. mays (Figure 4). As to the results, 14 syntenic blocks of orthologs were predicted between O. sativa and A. thaliana K+ channel genes (Figure 4A). Besides, OsAKT1 showed syntenic regions with three orthologs in Arabidopsis, including AtAKT1 (AT2G26650), AtAKT5 (AT4G32500), and AtAKT6 (AT2G25600), while OsKAT1 had synteny with three KATs from Arabidopsis, including AtKAT1 (AT5G46240), AtKAT2 (AT4G18290), and AtAKT2 (AT4G22200). The K+ channel genes in rice also showed an important syntenic relationship with their orthologs in the B. distachyon and S. bicolor genomes, with 6 and 10 syntenic regions, respectively (Figure 4B,C). OsAKT2 showed synteny with three $K+$ channel genes in S. bicolor. In this study, 18 syntenic blocks were predicted between $K+$ channel genes from rice and their orthologs in maize (Figure 4D). Overall, the most segmental duplications were predicted between $\mathrm{K}+$ channel orthologs 
in rice and maize. In the current study, Os09g02994 and Os03g0752300 were found in all syntenic blocks of orthologs, indicating that they are the most conserved genes in $\mathrm{K}+$ channel gene family.

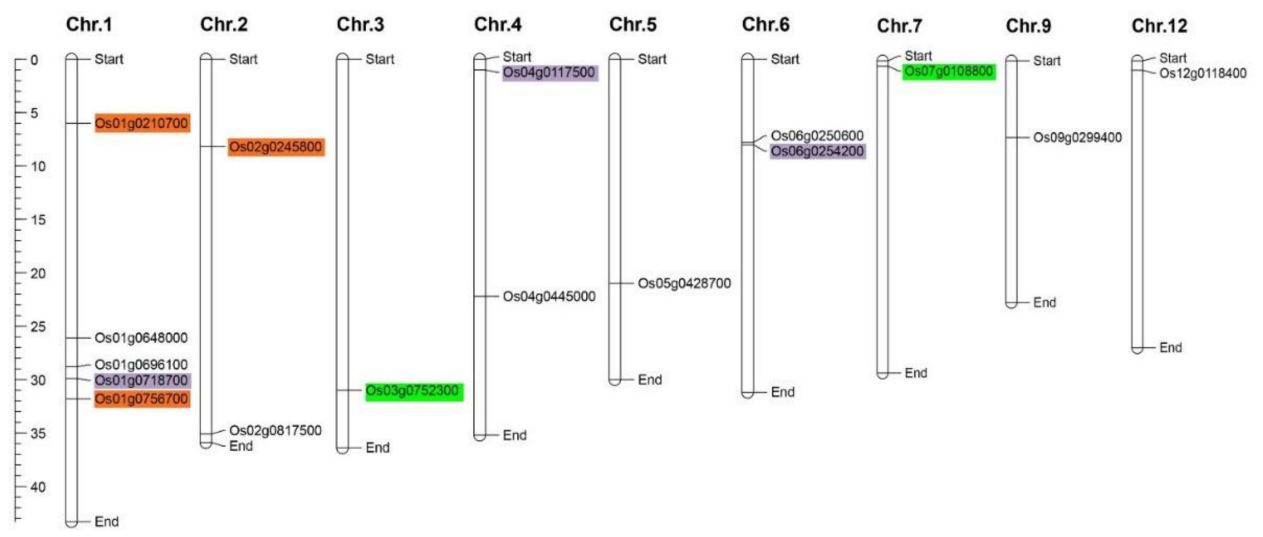

Figure 3. Location of $K+$ channel genes on the rice chromosomes. The pairs of segmentally duplicated genes are shown with the same color.
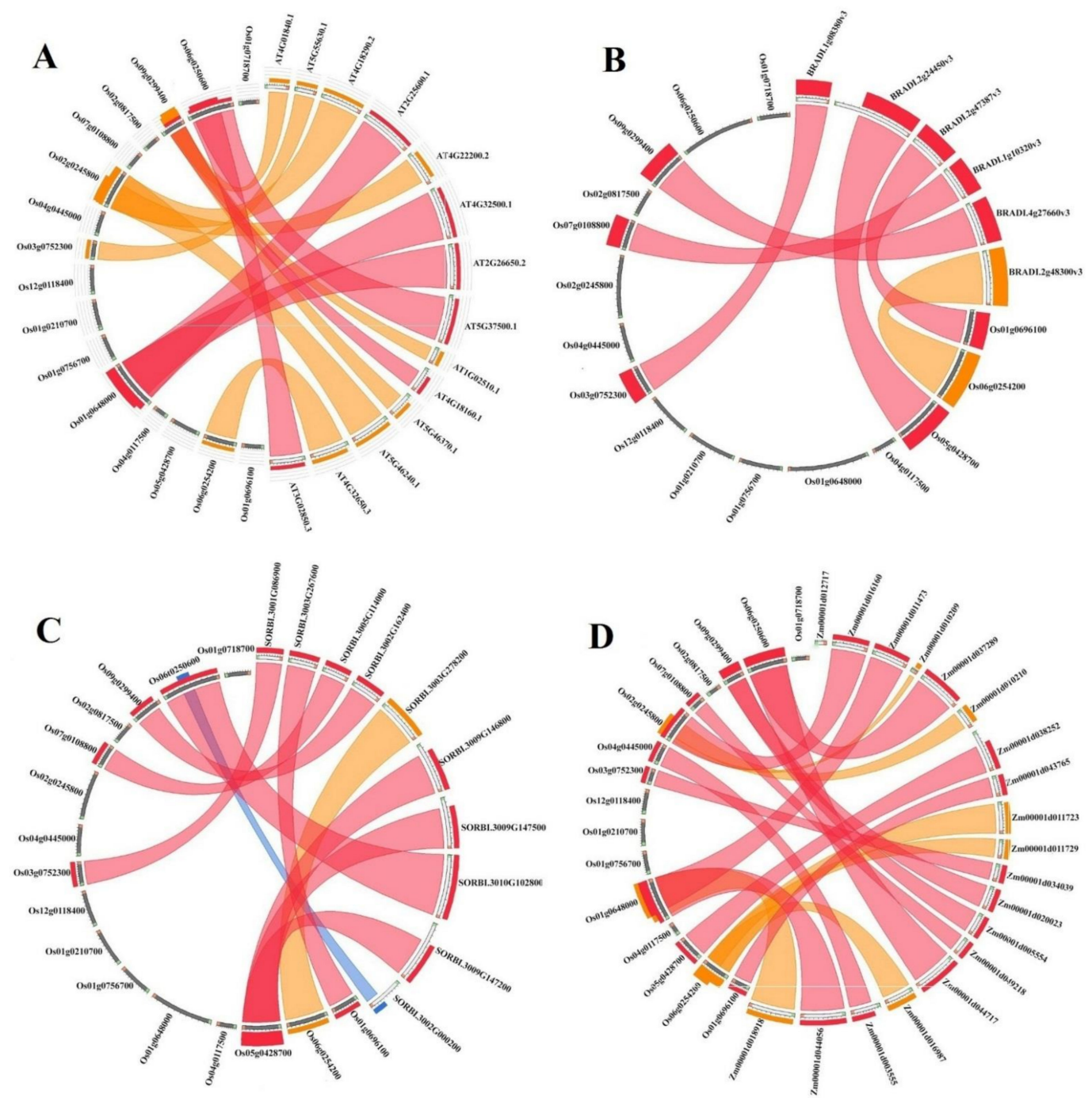

Figure 4. Synteny analysis of $K+$ channel genes. The syntenic blocks of rice $K+$ channel genes were compared with their orthologs in A. thaliana (A), B. distachyon (B), S. bicolor (C), and Z. mays (D). 


\subsection{D Protein Modeling and Docking Analysis of Ligand-Binding Regions}

The protein structures of all the candidate K+ channel proteins were modeled at $>90 \%$ confidence, and their potential active ligand-binding sites were also identified. According to the protein structure results, different active ligand-binding sites were predicted to be $\mathrm{K}+$ channel proteins (Figure S2). Some diversity in the protein structure may reflect their different roles in the transmembrane transport process in response to multiple environments. In addition, the binding region/active sites of $\mathrm{K}+$ channel proteins were predicted. Based on the results, different pockets were observed, and the key amino acids involved in the function of $\mathrm{K}+$ channel proteins were predicted (Figure 5). The LEU, VAL, TYR, SER, LYS, and THR amino acids were more predicted to be the binding residues in the ligand-binding site of nearly all candidate $\mathrm{K}+$ channel proteins (Figure 6A). The frequency of amino acid residues present in each pocket site was different between OsAKTs and OsKATs (Figure 6B). In OsAKTs, ASN and LEU were more frequently observed, while LEU and HIS were more frequently observed in pocket sites of OsKATs. Overall, LEU is recognized as the key residue in predicted pocket sites in $\mathrm{K}+$ channel proteins. In addition, OsKATs and OsAKTs are different based on pocket sites affecting on their functions. These results suggest the importance of these residues in these positions on the DNA molecule and, finally, the cellular functional performance.

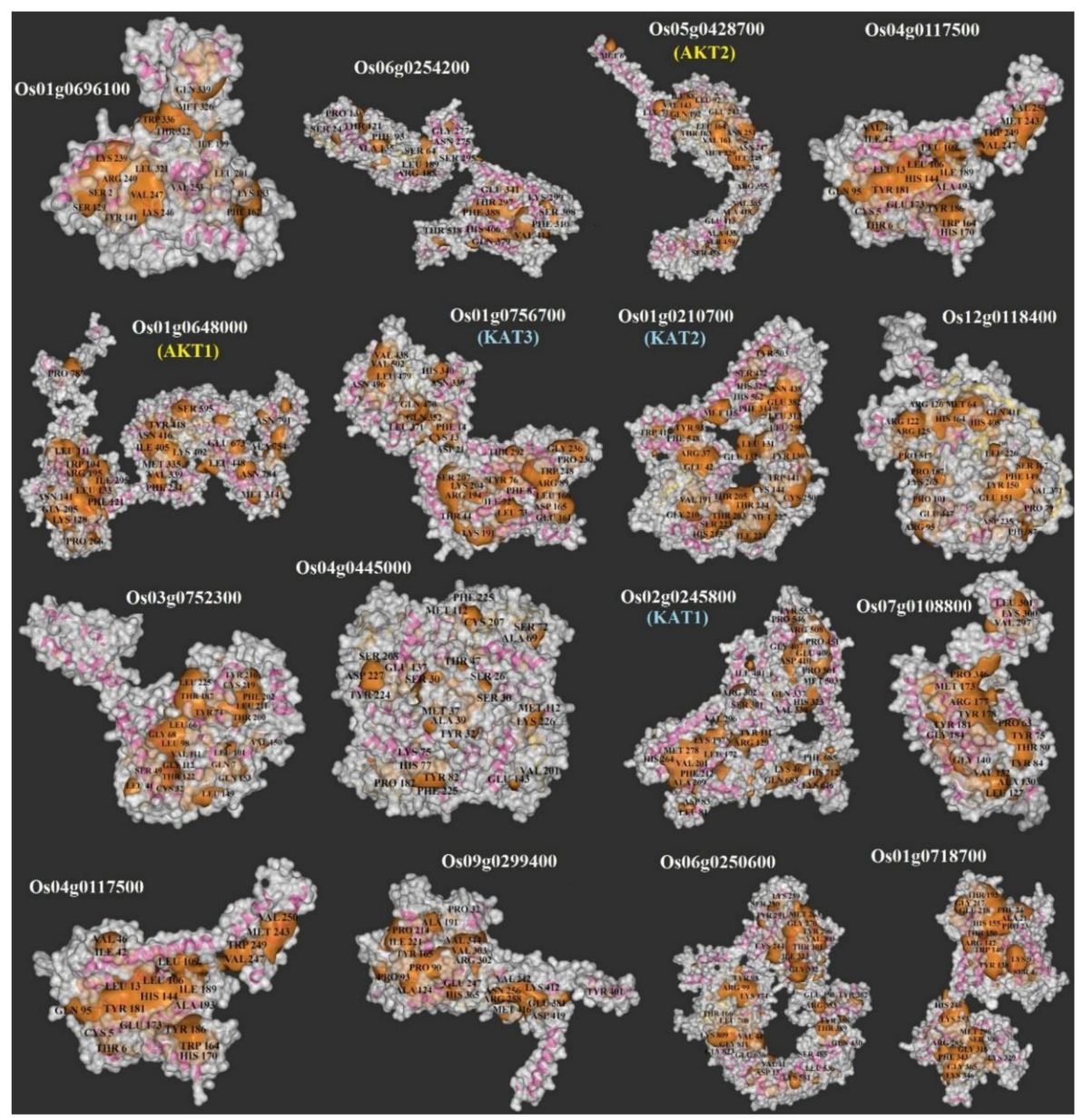

Figure 5. Docking analysis of pocket sites of $\mathrm{K}+$ channel proteins in rice. 

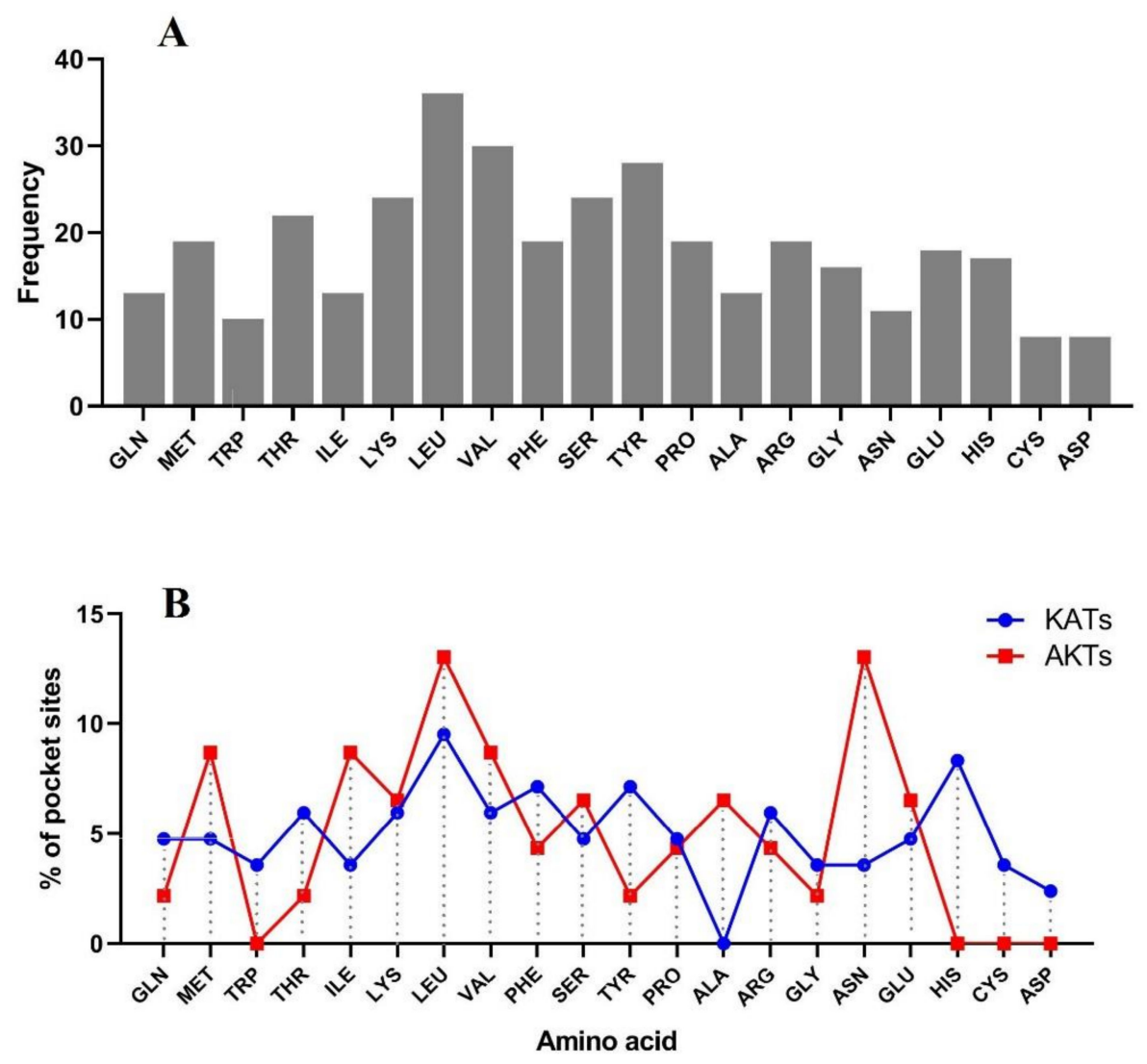

Figure 6. Distribution of ligand-binding sites in all studied $\mathrm{K}+$ channel proteins (A), and the percentage of each ligand-binding site in predicted pocket sites of the KATs and AKTs subfamily in rice (B).

\subsection{Prediction of Posttranslational Modifications}

The potential N-glycosylation sites of potassium channel proteins were predicted, as shown in Figure 7. Except for Os03g0752300, OsKTPs showed potential N-glycosylation at one to six sites. As for the N-glycosylation results, OsKAT1 was predicted to be a protein with many glycosylation sites (six sites), while one glycosylation site was predicted in OsKAT3, and three sites were predicted in OsKAT2 (Figure 7A). In addition, four Nglycosylation sites were observed in OsAKT1, and two sites were observed in OsAKT2. Regarding the results of predicted phosphorylation sites, potassium channel proteins showed a range from 21 (in Os01g0718700) to 83 sites (in OsKAT1) (Figure 7B). Furthermore, 41 and 40 sites were predicted in OsKAT2 and OsKAT3, respectively (Figure 7B). In AKTs, 48 sites in OsAKT2 and 78 sites in OsAKT1 were predicted. 
A
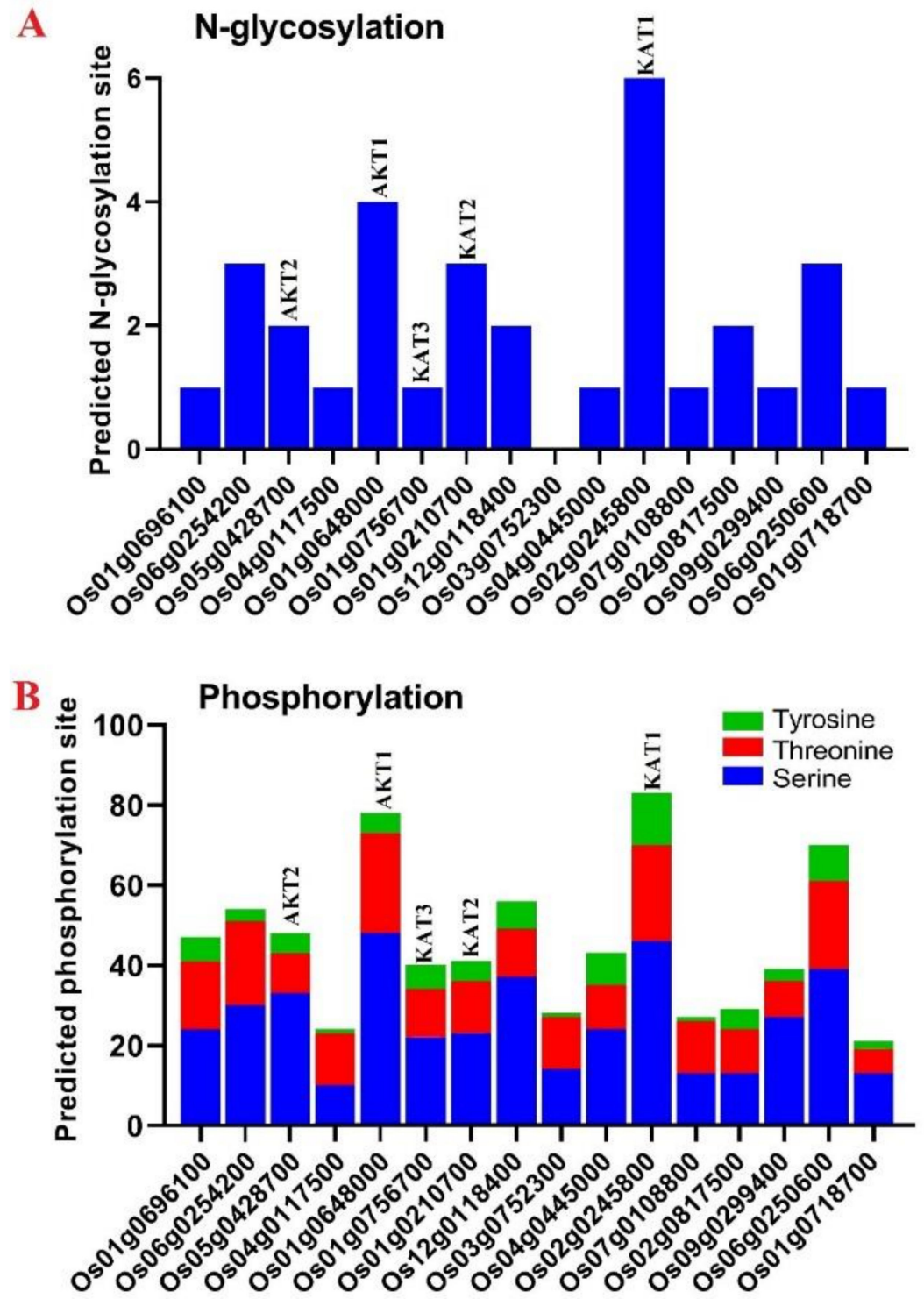

Figure 7. Prediction of posttranslational modifications in the amino acid sequences of $\mathrm{K}+$ channel proteins of rice in terms of the N-glycosylation site (A) and phosphorylation site (B).

\subsection{Expression Patterns of K+ Channel Genes in Different Tissues, Organs, and Stresses}

The expression levels of potassium channel genes in different tissues, as well as in response to environmental stresses (biotic and abiotic), were examined using available RNA-seq data (Figure 8). The K+ channel genes showed differential expression and tissuespecific expression patterns (Figure 8A). Os02g0817500, a voltage-dependent potassium channel, showed high expression in all rice tissues, especially in panicles, pistils, and pre-emergence inflorescences (Figure 8A). In addition, OsAKT1 was expressed in seeds and roots (Figure $8 \mathrm{~A}$ and $8 \mathrm{~B}$ ), while OsAKT2 was more highly expressed in leaves. Furthermore, the in silico expression profile of $K+$ channel genes was investigated under different stresses, including phosphate starvation (Pi), cadmium (Cd), drought (DR), salinity (S), and arsenic (As) stresses (Figure 8B). K+ channel genes showed differential expression in response to adverse conditions. For instance, OsAKT1 was upregulated in response to phosphate starvation $(\mathrm{Pi})$ in roots after $24 \mathrm{~h}$, while OsKAT1 was more induced in response to the rice pathogen $X$. oryzae in leaves (Figure $8 \mathrm{~B}$ ). In addition, OsKAT3 was not expressed under stress and showed high divergence from other OsKAT genes based on the expression profile. As to the RNA-seq data related to stress conditions, Os02g0817500 was detected as the $K+$ channel gene induced under all stimuli, while Os12g0118400 and Os03g0752300 were 
induced at a higher level in response to biotic stresses, indicating their important potential in stress resistance in rice (Figure $8 \mathrm{~B}$ ).

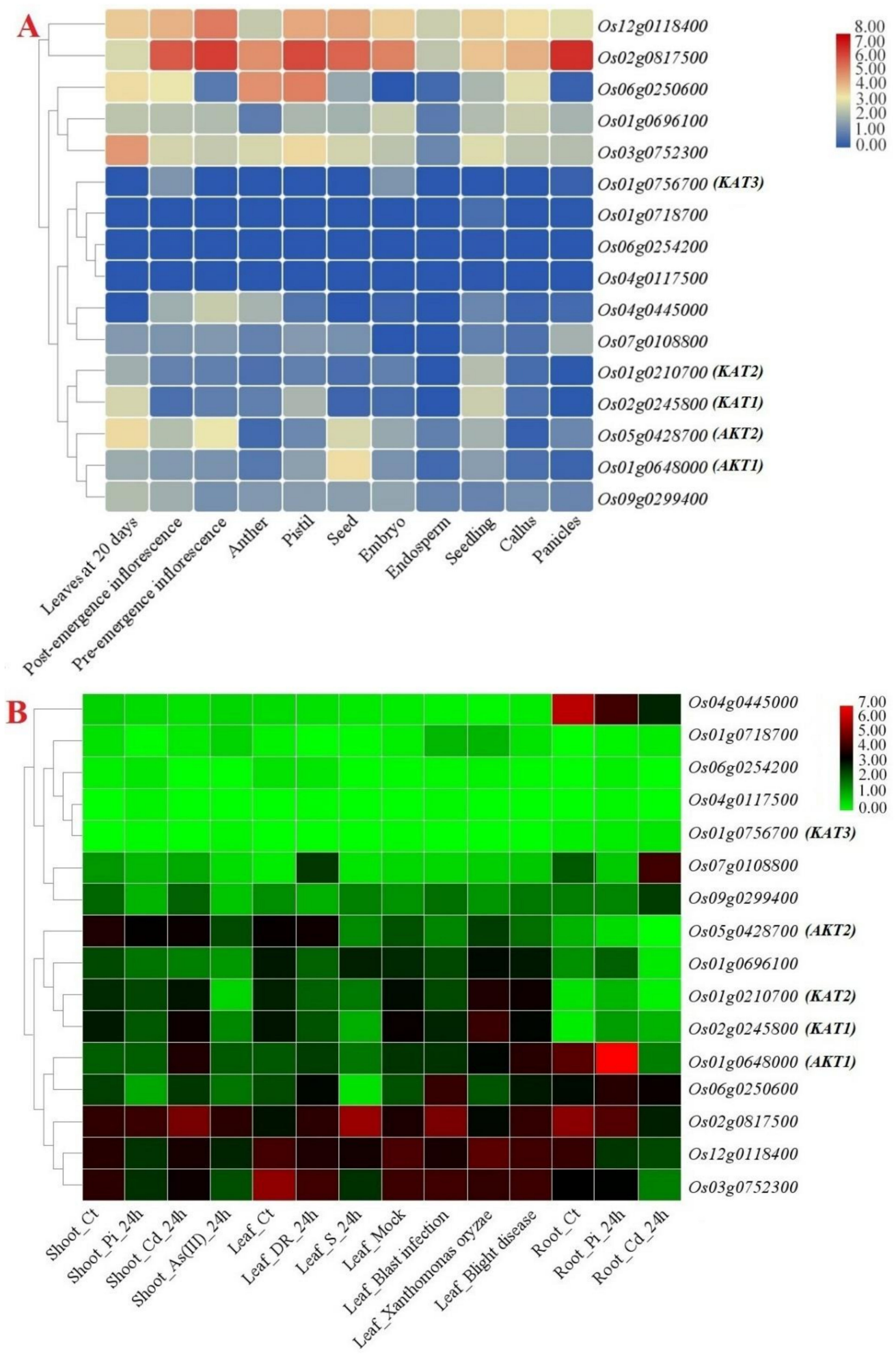

Figure 8. Expression heatmaps of $K+$ channel genes in rice from different tissues (A) and in response to abiotic and biotic stresses (B). The studied conditions included control (Ct); phosphate starvation (Pi), cadmium (Cd), drought (DR), salinity (S), and arsenic (As) stresses; and pathogens. Heatmaps were generated based on the log-2-transformed RNA-seq fragments per kilobase per million fragments mapped (FPKM) magnitudes in the exons of the rice genome. 


\subsection{Coexpression Network Analysis of K+ Channel Genes}

To obtain more insights regarding the $K+$ channel gene interactions with other genes in rice and their functional roles in plant cells, a co-expression network was constructed. As a result, 98 genes, clustered into the four co-expression nodes (A-D), were found in the co-expression network of $\mathrm{K}+$ channel genes (Figure 9). According to the KEGG ontology results, the co-expressed genes were found to be involved in amino sugar and nucleotide sugar metabolism (KEGG ID: Osa00520), purine metabolism (KEGG ID: Osa00230), carbon metabolism (KEGG ID: Osa01200), glycerophospholipid metabolism (KEGG ID: Osa00564), monoterpenoid biosynthesis (KEGG ID: Osa00902), fructose and mannose metabolism (KEGG ID: Osa00051), and folate biosynthesis (KEGG ID: Osa00790). Among the $K+$ channel genes, LOC4338660 (UDP-sulfoquinovose synthase) in node A and LOC4327472 (probable mannose-1-phosphate guanylyltransferase 2) and LOC4345021 (probable mannose-1-phosphate guanylyltransferase 3) in node B, as neighbors of the $K+$ channel genes LOC4351341 and LOC4334137, were involved in amino sugar and nucleotide sugar metabolism. LOC4333995 (lecithin-cholesterol acyltransferase-like 1) in node C and LOC4325310 (phosphatide cytidylyltransferase 1) in node B were identified as co-expressed genes involved in glycerophospholipid metabolism. In node D, LOC4336497 (salutaridine reductase) and LOC4348690 (probable cinnamyl alcohol dehydrogenase 3) were identified as co-expressed with the $\mathrm{K}+$ channel gene LOC4328864 in monoterpenoid biosynthesis. In node C, two genes, LOC4326296 (light-mediated development protein DET1) and LOC4352424 (E3 ubiquitin-protein ligase MIEL1), co-expressed with the $K+$ channel gene LOC4338867 (OsAKT2), were predicted to be engaged in ubiquitin-mediated proteolysis (Osa04120). LOC4328912 (cyclic nucleotide-gated ion channel 1) and LOC9266860 (probable calcium-binding protein CML18) were co-expressed with the K+ channel genes LOC4338867 and LOC4334137 in nodes C and B, respectively, and were predicted to be involved in the regulation of plant-pathogen interactions (Osa04626). Furthermore, LOC4336102 (indole-3glycerol phosphate synthase) and LOC4327301 (ATP-dependent 6-phosphofructokinase 6) were found to be co-expressed with the K+ channel genes LOC4351341 and LOC4334137 during the biosynthesis of amino acids (Osa01230). The co-expression results revealed that $K+$ channel genes have critical functions during rice growth and responding to stimuli.

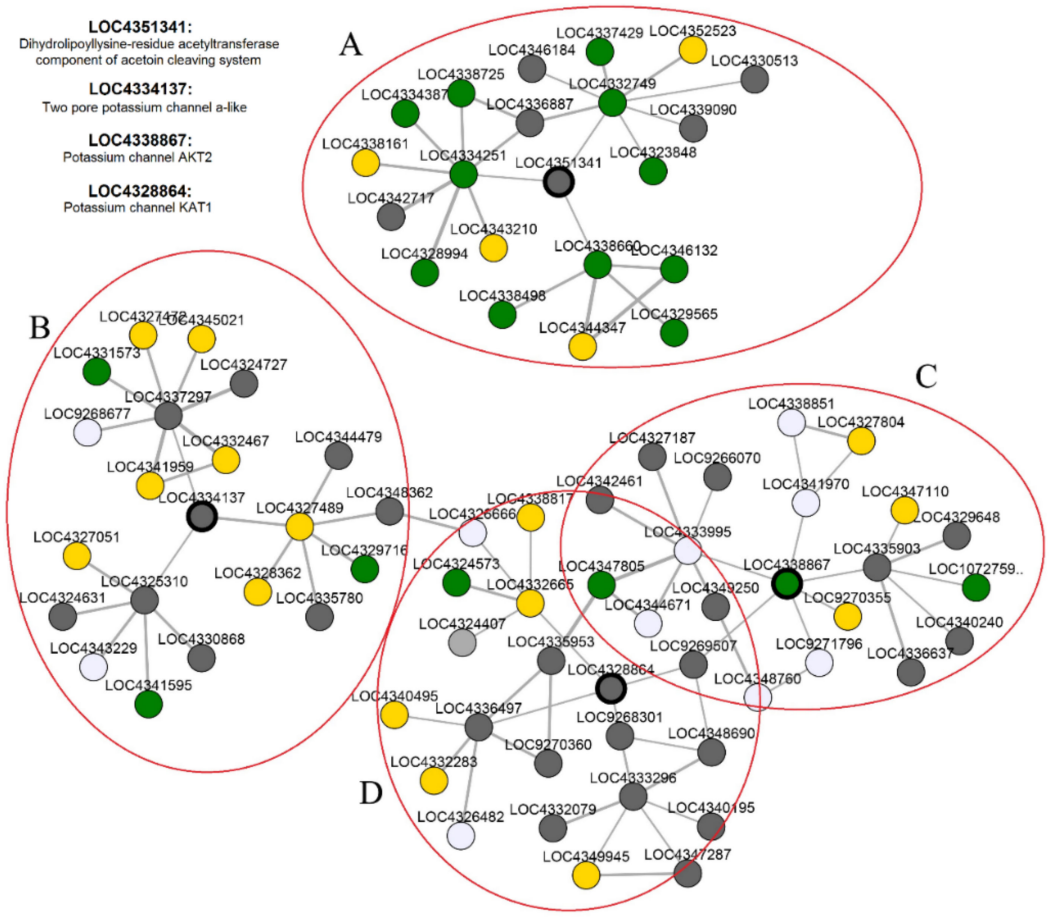

Figure 9. The co-expression network of $K+$ channel genes with other genes in rice. Ninety eight co-expressed genes clustered into the four co-expression nodes (A-D). 


\subsection{Expression of OsAKTs and OsKATs in Response to Salt Stress}

In the current study, OsAKT genes (OsAKT1 and OsAKT2) and OsKAT genes (OsKAT1, OsKAT2, and OsKAT3) were selected for further assays of their potential in the response to salt stress in root and shoot tissues of three rice cultivars. The OsAKTs and OsKATs showed specific tissue expression, although this expression was somewhat dependent on the type of rice cultivar. For instance, OsAKT1, OsAKT2, and OsKAT3 were more induced in shoot tissues of Sang Tarom, a tolerant cultivar, while all OsAKTs and OsKATs were upregulated in root tissues of the other two susceptible cultivars, IR29 and Jelodar, in response to salt stress (Figure 10). OsAKT1 showed an upregulation in roots after $72 \mathrm{~h}$ of salt stress in IR29 and 72 to $120 \mathrm{~h}$ after salt stress in the Jelodar cultivar, while it was highly downregulated after $168 \mathrm{~h}$ in shoot tissues in both cultivars, IR29 and Jelodar. However, OsAKT1 was downregulated at all time points of salt stress in root tissues of the Sang Tarom cultivar. OsAKT1 showed high expression in the early stage of salinity stress $(6 \mathrm{~h})$ in root tissues of IR29, and it was highly downregulated after $72 \mathrm{~h}$ in root tissues in all studied rice cultivars (Figure 10). Based on the real-time PCR results, OsKAT genes showed higher expression in root tissues compared to other tissues in response to salt stress. OsKAT3 showed a high expression in root tissues of the Jelodar cultivar after $120 \mathrm{~h}$ of salt stress and was upregulated at $6 \mathrm{~h}$ of salt stress in root tissues of IR29 and Jelodar and shoot tissues of Sang Tarom (Figure 10). It seems that OsKAT3 is involved in the early rice response to salt stress. In addition, OsKAT1 was significantly upregulated in response to long-term salt stress (after $120 \mathrm{~h}$ of salt stress) in root tissues of all studied rice cultivars, and OsKAT1 showed an approximately 35 -fold increase in expression after $120 \mathrm{~h}$ in the Jelodar cultivar. Furthermore, the highest expression of the OsKAT2 gene was observed in roots after 6 and $24 \mathrm{~h}$ of salinity treatment; after $24 \mathrm{~h}$ of salinity treatment, this gene showed a 27 -fold increase in expression compared to the control (Figure 10). Interestingly, all OsKAT genes were upregulated after $6 \mathrm{~h}$ of salt stress. Besides, OsKAT genes were more highly expressed in root tissues in rice, and their expression levels were repressed in shoot tissues under salt stress. Overall, it seems that the repression of the OsAKTs, OsKAT2, and OsKAT2 in roots is related to salinity tolerance in rice. 

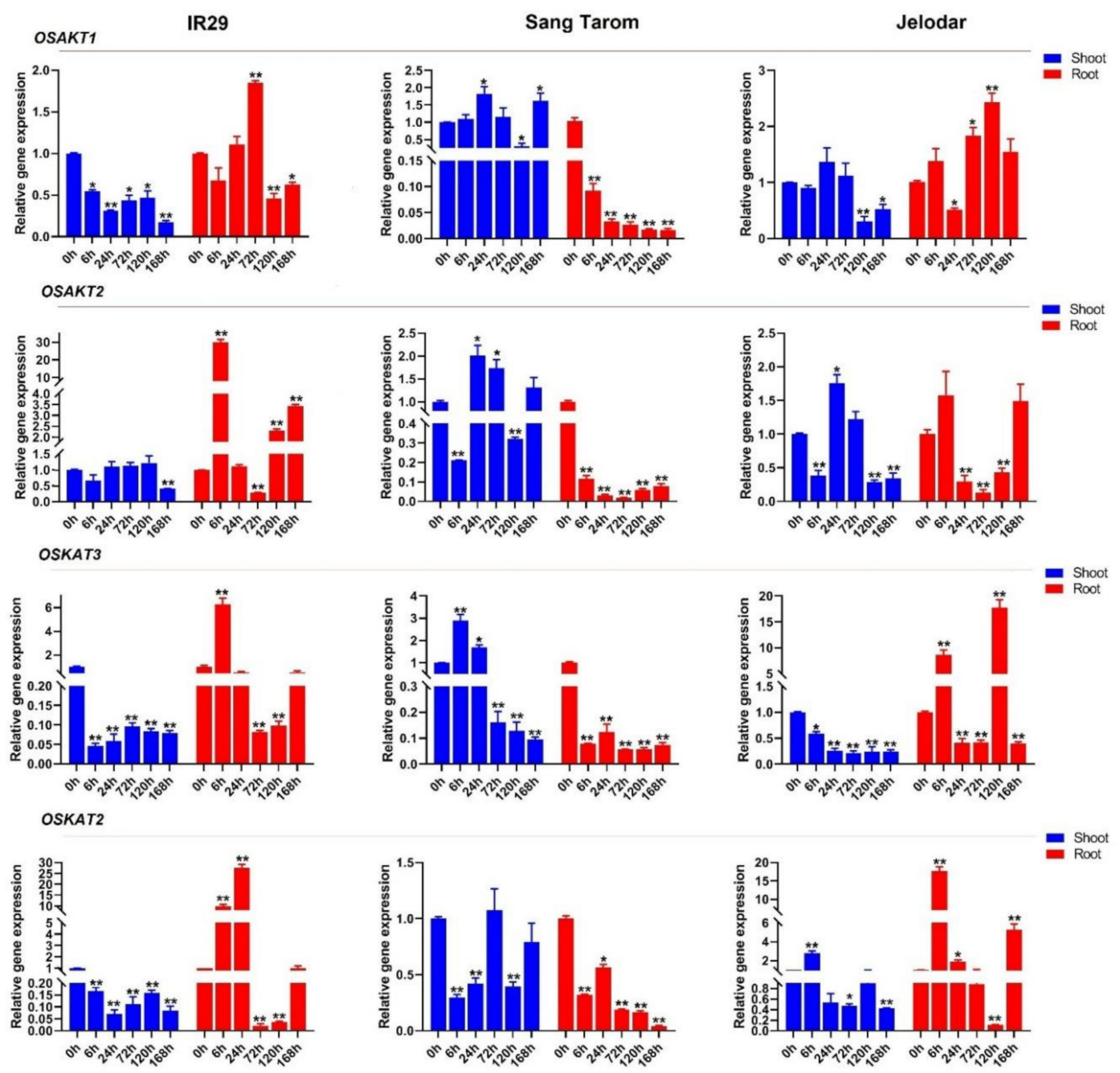

OSKAT1
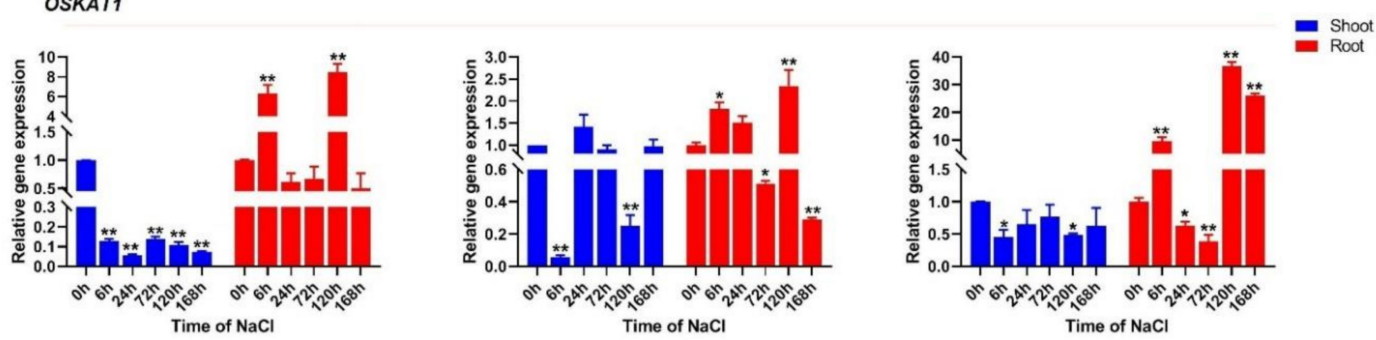

Figure 10. Relative expression levels of OsAKT genes (OsAKT1 and OsAKT2) and OsKAT genes (OsKAT1, OsKAT2, and OsKAT3) in the shoot and root tissues of three rice cultivars, IR29 (susceptible cultivar), Sang Tarom (moderately tolerant cultivar), and Jelodar (moderately susceptible cultivar), in response to $\mathrm{NaCl}$ stress at different time courses. The values are given as the means \pm SDs of three biological replicates, and the * and ${ }^{* *}$ above the bars show a significant difference (according to Student's $t$-test) between the applied treatments and the control at $p<0.05$ and $p<0.01$, respectively.

\section{Discussion}

Potassium $(\mathrm{K}+)$ is essential for plant growth and plays important roles in regulating cellular processes such as controlling $\mathrm{pH}$ and cell turgor [1,2]; potassium is involved in regulating the activity of many enzymes as an essential cofactor $[1,3,4] . \mathrm{K}+$ channels are involved in the transport and distribution of potassium in plant cells [1,12]. Many K+ channel genes have been characterized in different plant species [2,14,15]. In the current study, three OsKAT genes and two OsAKT genes, along with 11 nonredundant putative potassium channel genes in the rice genome, were characterized based on their physicochemical properties and sequences (Table 1). Potassium channel genes have diverse functions and structures. 
The exon number varied from 1 to 11 , and the pI ranged from 5.78 to 10.39. Diversity in their structures may affect their functions and interaction networks [63]. Regarding the phylogenetic results, a high diversity was observed between potassium channel proteins, and OsKATs showed high genetic divergence from other potassium channel proteins. A wide range of $K+$ channel genes have expanded during evolution and obtained diverse functions in plants [12]. A high diversity between potassium channel proteins indicates that the potassium channel gene family originated before the divergence of dicots and monocots [64,65].

The intraspecies synteny results showed that some of the duplicated blocks were collinear, such as Os01g0210700, Os01g0718700, and Os01g0756700, which may demonstrate chromosome segmentation or a large-scale duplication event. Furthermore, the nonsynonymous (Ka) and synonymous (Ks) substitution rates among the duplicated pairs can be considered an important index to assay the selection pressure and approximate duplication time. Because the $\mathrm{Ka} / \mathrm{Ks}$ ratios were $<1$ in duplicated gene pairs from the $\mathrm{K}+$ channel family in rice, it can be suggested that the genes underwent purifying selection [66]. These results significantly suggest that the genes with conserved functions and/or pseudogenization might be generated by purifying selection. As to the predicted motifs in $\mathrm{K}+$ channel proteins, it was found that the genes within the duplicated gene group could be functionally conserved. This can be attributed to one or more primeval polyploidy events in multiple angiosperm plant lineages. Therefore, these gene duplications in the rice genome result in the appearance of evolutionary novelties. The syntenic blocks in $K+$ channel genes were investigated across rice and several other plant species, and the closest orthologs of the $\mathrm{K}+$ channels in the rice genome were revealed to be from maize. These wide synteny relations among these species at the gene level were considered to confirm their close evolutionary relationships [67]. Some variations in these evolutionary relationships can illustrate the vast rearrangement events in rice and its related species during the genome evolution process.

Protein structures are precisely associated with the functions of genes and can reflect the phylogenetic relationships among them $[64,68]$. The protein structures of all the candidate $\mathrm{K}+$ channel proteins were modeled at $>90 \%$ confidence, and their potential active ligand-binding sites were also identified. Some diversity in these protein structures may reflect their different roles in the transmembrane transport process in response to multiple environments. Based on the three-dimensional structure analysis, it can be mentioned that these proteins from multiple clades belong to functionally diverse groups but share a common catalytic mechanism in the stabilization of membrane potential and cellular potassium ion homeostasis under stresses, supporting that $\mathrm{K}+$ channel proteins can play an important role in intracellular signaling pathways in the response to unfavorable conditions. In protein structures, channels, and cavities are significantly engaged in protein function adjustment and can vary their binding specificities $[64,69,70]$. This may suggest that $\mathrm{K}+$ channel evolutionary divergence can modulate the characteristics of the gene to function during various molecular pathways. The LEU, VAL, SER, PRO, HIS, GLY, LYS, TYR, CYC, and ARG amino acids were predicted as the binding residues in the ligand-binding site of nearly all candidate $\mathrm{K}+$ channel proteins, which may manifest the importance of these residues in those positions on the DNA molecule and their cellular functional performance. For instance, SER, VAL, PRO, and LEU have been identified as the key amino acids involved in regulating the responses to stress [71,72]. In addition, the potential posttranslational modifications of $\mathrm{K}+$ channel proteins were predicted in terms of $\mathrm{N}$-glycosylation and phosphorylation modifications. Glycosylation and phosphorylation modifications play vital roles in protein functions in eukaryotic organisms [73]. In the current study, OsKAT1 was predicted to be a protein with a high potential for $\mathrm{N}$-glycosylation and phosphorylation modifications. Glycosylation modifications may change the stability and molecular weight of the target protein [73,74]. In addition, phosphorylation modifications play critical roles in protein activity, protein-protein interactions, and the regulation of signal transduction $[65,75,76]$. Previous studies have revealed that posttranslational modifications such as 
phosphorylation are involved in activating the $\mathrm{K}+$ channel AKT1 [1,21,31]. Two calcium sensors, calcineurin B-like 1 (CBL1) and CBL2, with a CBL-interacting protein kinase (CIPK 23) are involved in AKT1 phosphorylation [21,77]. Posttranslational modifications may affect the function of K+ channel proteins, especially OsKAT1 and OsAKT1.

The study of co-expression networks reveals valuable information on the possible cellular pathways related to target genes [66]. In the present study, an interaction network of 98 genes c-oexpressed with $K+$ channel genes was constructed in rice. Base on the coexpression network, OsAKT2 can interact with genes involved in ubiquitin-mediated proteolysis, calcium signaling, and plant-pathogen interactions. Regarding the co-expression network and KEGG ontology results, several metabolic pathways, including amino sugar and nucleotide sugar metabolism, purine metabolism, carbon metabolism, glycerophospholipid metabolism, monoterpenoid biosynthesis, fructose and mannose metabolism, and folate biosynthesis, were recognized in the co-expression network. Regarding these results, $\mathrm{K}+$ channel proteins have critical functions during rice growth and stimuli processing. Due to the importance of potassium in plant growth and development, potassium channels in different tissues have been expanded for the proper distribution of $\mathrm{K}+$ in plant cells [78]. Based on the available RNA-seq data, K+ channel genes showed differential expression levels in different tissues in response to biotic and abiotic stresses. For instance, OsAKT1 is expressed in seeds and roots, while OsAKT2 is more highly expressed in leaves. It seems that the OsKAT and OsAKT genes are not specific to an organ/tissue and are expressed as key potassium channels in different tissues of rice. Furthermore, potassium channel genes showed differential expression in response to adverse conditions. As to the expression patterns, OsAKT1 was upregulated in response to phosphate starvation, while OsKAT1 was upregulated in response to the rice pathogen X. oryzae. In previous studies, the role of $A K T s$ and KATs in responding to abiotic stresses such as drought, salinity, osmotic stress, and iron toxicity was determined $[13,25,26,78]$. However, our findings reveal that OsAKTs and OsKATs are involved in the response to biotic stresses, which shows their importance in the resistance of rice to pathogens.

The relationship between potassium and sodium is a key factor in salt tolerance in plants, and increasing potassium accumulation in the cytoplasm reduces sodium toxicity to organelles $[2,13,26]$. Regarding the real-time PCR results, OsAKTs and OsKATs were induced by salt stress in the root and shoot tissues of rice cultivars. OsAKTs were more downregulated in response to salt stress, while OsKATs were sharply upregulated in root tissues in response to salt stress. In root tissues, $A K T 1$ can affect Na uptake, and suppression of $A K T 1$ reduces transpiration in guard cells $[79,80]$. Another previous study stated that the overexpression of OsAKT1 might improve rice tolerance to drought stress [81]. It seems that OsAKT1 downregulation is a part of the response of plants to salinity stress as well as drought stress. AKT2, as a potassium channel, contains two different gating modes and is involved in $\mathrm{K}+$ loading and unloading in the phloem [82-84]. It was stated that the activity of $A K T 2$ is suppressed by salt stress [85]. In the current study, OsKAT3 was identified as an early component of the rice response to salt stress, whereas OsKAT1 was recognized as a rice response to long-term salt stress in root tissues. However, all OsKAT genes were upregulated after $6 \mathrm{~h}$ of salt stress. It was reported that OsKAT1 might increase rice salinity tolerance [26]. In addition, Moon et al. found that OsKAT2 is involved in drought tolerance in rice by affecting stomatal opening [25]. The function of OsKAT3 is still unknown, and its role in responding to environmental stresses such as salinity has not been determined. Overall, our results revealed that OsKAT1 has a high potential for regulating the response of rice to salinity stress. Furthermore, the results of the prediction of posttranslational modifications and co-expression networks indicated that OsKAT1 is involved in different cellular signaling pathways related to plant tolerance and can be used in future rice molecular breeding programs related to increasing salinity tolerance. 


\section{Conclusions}

Potassium channels are key transporters involved in the distribution of potassium in plant cells. In the present study, OsKAT and OsAKT genes, along with 11 potassium channel members in the rice genome, were widely characterized. Our genomic results showed that potassium channel genes are differentiated in their functions and structures. Furthermore, our bioinformatic analyses revealed new insights into regulatory systems and interaction networks of potassium channel genes in rice. Our findings revealed that repression of OsAKTs, OsKAT2, and OsKAT2 in roots is related to salinity tolerance in rice. Moreover, OsKAT1 is identified as a key gene involved in the rice response to salt stress, and its allelic variants may be used as genetic markers in future rice breeding programs.

Supplementary Materials: The following are available online at https://www.mdpi.com/article/ 10.3390/genes12050784/s1, Table S1: List of designed primers for real-time PCR; Table S2: List of conserved motifs predicted in potassium channel protein sequences of rice; Table S3: The predicted duplicated gene pairs in the potassium channel protein family in rice; Figure S1: Synteny analysis of $\mathrm{K}+$ channel genes in rice; Figure S2: The protein channel regions predicted in $\mathrm{K}+$ channel proteins in rice.

Author Contributions: Conceptualization, Z.M. and H.N.-Z.; methodology, Z.M., S.K.K., and S.H.H.; software, S.F. and P.H.; formal analysis, S.F., S.H.H., and P.H.; investigation, G.B. and P.H. All authors contributed to writing and editing the manuscript. All authors have read and agreed to the published version of the manuscript.

Funding: This research received no external funding.

Institutional Review Board Statement: Not applicable.

Informed Consent Statement: Not applicable.

Conflicts of Interest: The authors declare no conflict of interest.

\section{References}

1. Sanchez-Barrena, M.J.; Chaves-Sanjuan, A.; Raddatz, N.; Mendoza, I.; Cortes, A.; Gago, F.; Gonzalez-Rubio, J.M.; Benavente, J.L.; Quintero, F.J.; Pardo, J.M. Recognition and activation of the plant AKT1 potassium channel by the kinase CIPK23. Plant Physiol. 2020, 182, 2143-2153. [CrossRef]

2. Amrutha, R.N.; Sekhar, P.N.; Varshney, R.K.; Kishor, P.B.K. Genome-wide analysis and identification of genes related to potassium transporter families in rice (Oryza sativa L.). Plant Sci. 2007, 172, 708-721. [CrossRef]

3. Dreyer, I.; Uozumi, N. Potassium channels in plant cells. FEBS J. 2011, 278, 4293-4303. [CrossRef]

4. Chérel, I.; Gaillard, I. The complex fine-tuning of $\mathrm{K}^{+}$fluxes in plants in relation to osmotic and ionic abiotic stresses. Int. J. Mol. Sci. 2019, 20, 715. [CrossRef]

5. Very, A.-A.; Sentenac, H. Molecular mechanisms and regulation of $\mathrm{K}^{+}$transport in higher plants. Annu. Rev. Plant Biol. 2003, 54, 575-603. [CrossRef]

6. Alemán, F.; Caballero, F.; Ródenas, R.; Rivero, R.M.; Martínez, V.; Rubio, F. The F130S point mutation in the Arabidopsis high-affinity $\mathrm{K}^{+}$transporter AtHAK5 increases $\mathrm{K}^{+}$over $\mathrm{Na}^{+}$and $\mathrm{Cs}^{+}$selectivity and confers $\mathrm{Na}^{+}$and $\mathrm{Cs}^{+}$tolerance to yeast under heterologous expression. Front. Plant Sci. 2014, 5, 430. [CrossRef] [PubMed]

7. Maierhofer, T.; Diekmann, M.; Offenborn, J.N.; Lind, C.; Bauer, H.; Hashimoto, K.; Al-Rasheid, K.A.S.; Luan, S.; Kudla, J.; Geiger, D. Site-and kinase-specific phosphorylation-mediated activation of SLAC1, a guard cell anion channel stimulated by abscisic acid. Sci. Signal. 2014, 7, ra86. [CrossRef] [PubMed]

8. Shabala, S.; Pottosin, I. Regulation of potassium transport in plants under hostile conditions: Implications for abiotic and biotic stress tolerance. Physiol. Plant. 2014, 151, 257-279. [CrossRef] [PubMed]

9. Luan, M.; Tang, R.; Tang, Y.; Tian, W.; Hou, C.; Zhao, F.; Lan, W.; Luan, S. Transport and homeostasis of potassium and phosphate: Limiting factors for sustainable crop production. J. Exp. Bot. 2017, 68, 3091-3105. [CrossRef] [PubMed]

10. Leigh, R.A.; Wyn Jones, R.G. A hypothesis relating critical potassium concentrations for growth to the distribution and functions of this ion in the plant cell. New Phytol. 1984, 97, 1-13. [CrossRef]

11. Benito, B.; Haro, R.; Amtmann, A.; Cuin, T.A.; Dreyer, I. The twins $\mathrm{K}^{+}$and $\mathrm{Na}^{+}$in plants. J. Plant Physiol. 2014, $171,723-731$. [CrossRef] [PubMed]

12. Sustr, M.; Soukup, A.; Tylova, E. Potassium in root growth and development. Plants 2019, 8, 435. [CrossRef] [PubMed]

13. Ahanger, M.A.; Tomar, N.S.; Tittal, M.; Argal, S.; Agarwal, R.M. Plant growth under water/salt stress: ROS production; antioxidants and significance of added potassium under such conditions. Physiol. Mol. Biol. Plants 2017, 23, 731-744. [CrossRef] [PubMed] 
14. Baizabal-Aguirre, V.M.; Clemens, S.; Uozumi, N.; Schroeder, J.I. Suppression of inward-rectifying K ${ }^{+}$channels KAT1 and AKT2 by dominant negative point mutations in the KAT1 $\alpha$-subunit. J. Membr. Biol. 1999, 167, 119-125. [CrossRef]

15. Szczerba, M.W.; Britto, D.T.; Kronzucker, H.J. $\mathrm{K}^{+}$transport in plants: Physiology and molecular biology. J. Plant Physiol. 2009, 166, 447-466. [CrossRef]

16. Jegla, T.; Busey, G.; Assmann, S.M. Evolution and structural characteristics of plant voltage-gated $\mathrm{K}^{+}$channels. Plant Cell 2018, 30, 2898-2909. [CrossRef]

17. Dreyer, I.; Vergara-Jaque, A.; Riedelsberger, J.; González, W. Exploring the fundamental role of potassium channels in novel model plants. J. Exp. Bot. 2019, 70, 5985-5989. [CrossRef]

18. Anderson, J.A.; Huprikar, S.S.; Kochian, L.V.; Lucas, W.J.; Gaber, R.F. Functional expression of a probable Arabidopsis thaliana potassium channel in Saccharomyces cerevisiae. Proc. Natl. Acad. Sci. USA 1992, 89, 3736-3740. [CrossRef]

19. Schachtman, D.P.; Schroeder, J.I.; Lucas, W.J.; Anderson, J.A.; Gaber, R.F. Expression of an inward-rectifying potassium channel by the Arabidopsis KAT1 cDNA. Science 1992, 258, 1654-1658. [CrossRef]

20. Sentenac, H.; Bonneaud, N.; Minet, M.; Lacroute, F.; Salmon, J.-M.; Gaymard, F.; Grignon, C. Cloning and expression in yeast of a plant potassium ion transport system. Science 1992, 256, 663-665. [CrossRef]

21. Xu, J.; Li, H.-D.; Chen, L.-Q.; Wang, Y.; Liu, L.-L.; He, L.; Wu, W.-H. A protein kinase, interacting with two calcineurin B-like proteins, regulates $\mathrm{K}^{+}$transporter AKT1 in Arabidopsis. Cell 2006, 125, 1347-1360. [CrossRef]

22. Alemán, F.; Nieves-Cordones, M.; Martínez, V.; Rubio, F. Root $\mathrm{K}^{+}$acquisition in plants: The Arabidopsis thaliana model. Plant Cell Physiol. 2011, 52, 1603-1612. [CrossRef] [PubMed]

23. Ache, P.; Becker, D.; Ivashikina, N.; Dietrich, P.; Roelfsema, M.R.G.; Hedrich, R. GORK, a delayed outward rectifier expressed in guard cells of Arabidopsis thaliana, is a $\mathrm{K}^{+}$-selective, $\mathrm{K}^{+}$-sensing ion channel. FEBS Lett. 2000, 486, 93-98. [CrossRef]

24. Hosy, E.; Vavasseur, A.; Mouline, K.; Dreyer, I.; Gaymard, F.; Porée, F.; Boucherez, J.; Lebaudy, A.; Bouchez, D.; Véry, A.-A. The Arabidopsis outward $\mathrm{K}^{+}$channel GORK is involved in regulation of stomatal movements and plant transpiration. Proc. Natl. Acad. Sci. USA 2003, 100, 5549-5554. [CrossRef] [PubMed]

25. Moon, S.-J.; Kim, H.Y.; Hwang, H.; Kim, J.; Lee, Y.; Min, M.K.; Yoon, I.S.; Kwon, T.-R.; Kim, B.-G. A dominant negative OsKAT2 mutant delays light-induced stomatal opening and improves drought tolerance without yield penalty in rice. Front. Plant Sci. 2017, 8, 772. [CrossRef] [PubMed]

26. Obata, T.; Kitamoto, H.K.; Nakamura, A.; Fukuda, A.; Tanaka, Y. Rice shaker potassium channel OsKAT1 confers tolerance to salinity stress on yeast and rice cells. Plant Physiol. 2007, 144, 1978-1985. [CrossRef]

27. Isayenkov, S.V.; Maathuis, F.J.M. Plant salinity stress: Many unanswered questions remain. Front. Plant Sci. 2019, 10, 80. [CrossRef]

28. Golldack, D.; Quigley, F.; Michalowski, C.B.; Kamasani, U.R.; Bohnert, H.J. Salinity stress-tolerant and-sensitive rice (Oryza sativa L.) regulate AKT1-type potassium channel transcripts differently. Plant Mol. Biol. 2003, 51, 71-81. [CrossRef]

29. Marten, I.; Hoth, S.; Deeken, R.; Ache, P.; Ketchum, K.A.; Hoshi, T.; Hedrich, R. AKT3, a phloem-localized K ${ }^{+}$channel, is blocked by protons. Proc. Natl. Acad. Sci. USA 1999, 96, 7581-7586. [CrossRef] [PubMed]

30. Maathuis, F.J.M. The role of monovalent cation transporters in plant responses to salinity. J. Exp. Bot. 2006, 57, 1137-1147. [CrossRef]

31. Li, J.; Long, Y.; Qi, G.-N.; Xu, Z.-J.; Wu, W.-H.; Wang, Y. The Os-AKT1 channel is critical for $\mathrm{K}^{+}$uptake in rice roots and is modulated by the rice CBL1-CIPK23 complex. Plant Cell 2014, 26, 3387-3402. [CrossRef]

32. Finn, R.D.; Mistry, J.; Tate, J.; Coggill, P.; Heger, A.; Pollington, J.E.; Gavin, O.L.; Gunasekaran, P.; Ceric, G.; Forslund, K. The Pfam protein families database. Nucleic Acids Res. 2010, 38, D211-D222. [CrossRef]

33. Schultz, J.; Copley, R.R.; Doerks, T.; Ponting, C.P.; Bork, P. SMART: A web-based tool for the study of genetically mobile domains. Nucleic Acids Res. 2000, 28, 231-234. [CrossRef] [PubMed]

34. Bolser, D.M.; Staines, D.M.; Perry, E.; Kersey, P.J. Ensembl plants: Integrating tools for visualizing, mining, and analyzing plant genomic data. In Plant Genomics Databases; Springer: New York, NY, USA, 2017; pp. 1-31.

35. Gasteiger, E.; Hoogland, C.; Gattiker, A.; Duvaud, S.; Wilkins, M.R.; Appel, R.D.; Bairoch, A. Protein identification and analysis tools on the ExPASy server. In The Proteomics Protocols Handbook; Humana Press: Totowa, NJ, USA, 2005; pp. 571-607.

36. Kumar, S.; Stecher, G.; Li, M.; Knyaz, C.; Tamura, K. MEGA X: Molecular evolutionary genetics analysis across computing platforms. Mol. Biol. Evol. 2018, 35, 1547-1549. [CrossRef]

37. Bailey, T.L.; Boden, M.; Buske, F.A.; Frith, M.; Grant, C.E.; Clementi, L.; Ren, J.; Li, W.W.; Noble, W.S. MEME SUITE: Tools for motif discovery and searching. Nucleic Acids Res. 2009, 37, W202-W208. [CrossRef] [PubMed]

38. Hu, B.; Jin, J.; Guo, A.-Y.; Zhang, H.; Luo, J.; Gao, G. GSDS 2.0: An upgraded gene feature visualization server. Bioinformatics 2015, 31, 1296-1297. [CrossRef] [PubMed]

39. Voorrips, R.E. MapChart: Software for the graphical presentation of linkage maps and QTLs. J. Hered. 2002, 93, 77-78. [CrossRef]

40. Larkin, M.A.; Blackshields, G.; Brown, N.P.; Chenna, R.; McGettigan, P.A.; McWilliam, H.; Valentin, F.; Wallace, I.M.; Wilm, A.; Lopez, R. Clustal W and Clustal X version 2.0. Bioinformatics 2007, 23, 2947-2948. [CrossRef] [PubMed]

41. Hall, T.A. BioEdit: A User-Friendly Biological Sequence Alignment Editor and Analysis Program for Windows 95/98/NT. In Proceedings of the Nucleic Acids Symposium Series; c1979-c2000. Information Retrieval Ltd.: London, UK, 1999; Volume 41, pp. 95-98. 
42. Rozas, J.; Ferrer-Mata, A.; Sánchez-DelBarrio, J.C.; Guirao-Rico, S.; Librado, P.; Ramos-Onsins, S.E.; Sánchez-Gracia, A. DnaSP 6: DNA sequence polymorphism analysis of large data sets. Mol. Biol. Evol. 2017, 34, 3299-3302. [CrossRef] [PubMed]

43. Yang, S.; Zhang, X.; Yue, J.-X.; Tian, D.; Chen, J.-Q. Recent duplications dominate NBS-encoding gene expansion in two woody species. Mol. Genet. Genom. 2008, 280, 187-198. [CrossRef]

44. Krzywinski, M.; Schein, J.; Birol, I.; Connors, J.; Gascoyne, R.; Horsman, D.; Jones, S.J.; Marra, M.A. Circos: An information aesthetic for comparative genomics. Genome Res. 2009, 19, 1639-1645. [CrossRef] [PubMed]

45. Obayashi, T.; Aoki, Y.; Tadaka, S.; Kagaya, Y.; Kinoshita, K. ATTED-II in 2018: A plant coexpression database based on investigation of the statistical property of the mutual rank index. Plant Cell Physiol. 2018, 59, e3. [CrossRef]

46. Franz, M.; Lopes, C.T.; Huck, G.; Dong, Y.; Sumer, O.; Bader, G.D. Cytoscape. js: A graph theory library for visualisation and analysis. Bioinformatics 2016, 32, 309-311.

47. Kelley, L.A.; Mezulis, S.; Yates, C.M.; Wass, M.N.; Sternberg, M.J.E. The Phyre2 web portal for protein modeling, prediction and analysis. Nat. Protoc. 2015, 10, 845-858. [CrossRef]

48. Lovell, S.C.; Davis, I.W.; Arendall, W.B., III; De Bakker, P.I.W.; Word, J.M.; Prisant, M.G.; Richardson, J.S.; Richardson, D.C. Structure validation by $C \alpha$ geometry: $\phi, \psi$ and $C \beta$ deviation. Proteins Struct. Funct. Bioinform. 2003, 50, 437-450. [CrossRef]

49. Tian, W.; Chen, C.; Lei, X.; Zhao, J.; Liang, J. CASTp 3.0: Computed atlas of surface topography of proteins. Nucleic Acids Res. 2018, 46, W363-W367. [CrossRef]

50. Jiménez, J.; Doerr, S.; Martínez-Rosell, G.; Rose, A.S.; De Fabritiis, G. DeepSite: Protein-binding site predictor using 3Dconvolutional neural networks. Bioinformatics 2017, 33, 3036-3042. [CrossRef] [PubMed]

51. DeLano, W.L. Pymol: An open-source molecular graphics tool. CCP4 Newsl. Protein Crystallogr. 2002, 40, 82-92.

52. Xia, L.; Zou, D.; Sang, J.; Xu, X.; Yin, H.; Li, M.; Wu, S.; Hu, S.; Hao, L.; Zhang, Z. Rice Expression Database (RED): An integrated RNA-Seq-derived gene expression database for rice. J. Genet. Genom. 2017, 44, 235-241. [CrossRef] [PubMed]

53. Oono, Y.; Yazawa, T.; Kawahara, Y.; Kanamori, H.; Kobayashi, F.; Sasaki, H.; Mori, S.; Wu, J.; Handa, H.; Itoh, T. Genome-wide transcriptome analysis reveals that cadmium stress signaling controls the expression of genes in drought stress signal pathways in rice. PLOS ONE 2014, 9, e96946. [CrossRef]

54. Secco, D.; Jabnoune, M.; Walker, H.; Shou, H.; Wu, P.; Poirier, Y.; Whelan, J. Spatio-temporal transcript profiling of rice roots and shoots in response to phosphate starvation and recovery. Plant Cell 2013, 25, 4285-4304. [CrossRef] [PubMed]

55. Shankar, R.; Bhattacharjee, A.; Jain, M. Transcriptome analysis in different rice cultivars provides novel insights into desiccation and salinity stress responses. Sci. Rep. 2016, 6, 23719. [CrossRef] [PubMed]

56. Bagnaresi, P.; Biselli, C.; Orrù, L.; Urso, S.; Crispino, L.; Abbruscato, P.; Piffanelli, P.; Lupotto, E.; Cattivelli, L.; Valè, G. Comparative transcriptome profiling of the early response to Magnaporthe oryzae in durable resistant vs susceptible rice (Oryza sativa L.) genotypes. PLoS ONE 2012, 7, e51609. [CrossRef] [PubMed]

57. Hong, H.; Liu, Y.; Zhang, H.; Xiao, J.; Li, X.; Wang, S. Small RNAs and gene network in a durable disease resistance geneMediated defense responses in rice. PLoS ONE 2015, 10, e0137360. [CrossRef]

58. Chen, C.; Chen, H.; Zhang, Y.; Thomas, H.R.; Frank, M.H.; He, Y.; Xia, R. TBtools: An Integrative Toolkit Developed for Interactive Analyses of Big Biological Data. Mol. Plant 2020, 13, 1194-1202. [CrossRef] [PubMed]

59. Yoshida, S. Routine procedure for growing rice plants in culture solution. In Laboratory Manual for Physiological Studies of Rice; International Rice Research Institute: Los Baños, CA, USA, 1976; pp. 61-66.

60. Livak, K.J.; Schmittgen, T.D. Analysis of relative gene expression data using real-time quantitative PCR and the $2-\Delta \Delta C T$ method. Methods 2001, 25, 402-408. [CrossRef] [PubMed]

61. Liu, Z.; Liu, Y.; Coulter, J.A.; Shen, B.; Li, Y.; Li, C.; Cao, Z.; Zhang, J. The WD40 Gene Family in Potato (Solanum Tuberosum L.): Genome-Wide Analysis and Identification of Anthocyanin and Drought-Related WD40s. Agronomy 2020, 10, 401. [CrossRef]

62. Zhang, J. Evolution by gene duplication: An update. Trends Ecol. Evol. 2003, 18, 292-298. [CrossRef]

63. Ahmadizadeh, M.; Rezaee, S.; Heidari, P. Genome-wide characterization and expression analysis of fatty acid desaturase gene family in Camelina sativa. Gene Rep. 2020, 21, 100894. [CrossRef]

64. Faraji, S.; Filiz, E.; Kazemitabar, S.K.; Vannozzi, A.; Palumbo, F.; Barcaccia, G.; Heidari, P. The AP2/ERF Gene Family in Triticum durum: Genome-Wide Identification and Expression Analysis under Drought and Salinity Stresses. Genes 2020, 11, 1464. [CrossRef]

65. Heidari, P.; Mazloomi, F.; Nussbaumer, T.; Barcaccia, G. Insights into the SAM Synthetase Gene Family and Its Roles in Tomato Seedlings under Abiotic Stresses and Hormone Treatments. Plants 2020, 9, 586. [CrossRef] [PubMed]

66. Faraji, S.; Ahmadizadeh, M.; Heidari, P. Genome-wide comparative analysis of Mg transporter gene family between Triticum turgidum and Camelina sativa. BioMetals 2021, 4, 639-660. [CrossRef]

67. Yang, Z.; Gu, S.; Wang, X.; Li, W.; Tang, Z.; Xu, C. Molecular evolution of the CPP-like gene family in plants: Insights from comparative genomics of Arabidopsis and rice. J. Mol. Evol. 2008, 67, 266-277. [CrossRef] [PubMed]

68. Zhang, S.; Yang, W.; Zhao, Q.; Zhou, X.; Jiang, L.; Ma, S.; Liu, X.; Li, Y.; Zhang, C.; Fan, Y. Analysis of weighted co-regulatory networks in maize provides insights into new genes and regulatory mechanisms related to inositol phosphate metabolism. $B M C$ Genomics 2016, 17, 1-17. [CrossRef] [PubMed]

69. Braun, P.; Aubourg, S.; Van Leene, J.; De Jaeger, G.; Lurin, C. Plant protein interactomes. Annu. Rev. Plant Biol. 2013, 64, 161-187. [CrossRef]

70. Fukao, Y. Protein-protein interactions in plants. Plant Cell Physiol. 2012, 53, 617-625. [CrossRef] 
71. Beauregard, M.; Hefford, M.A. Enhancement of essential amino acid contents in crops by genetic engineering and protein design. Plant Biotechnol. J. 2006, 4, 561-574. [CrossRef]

72. Galili, G.; Höfgen, R. Metabolic engineering of amino acids and storage proteins in plants. Metab. Eng. 2002, 4, 3-11. [CrossRef]

73. Heidari, P.; Ahmadizadeh, M.; Izanlo, F.; Nussbaumer, T. In silico study of the CESA and CSL gene family in Arabidopsis thaliana and Oryza sativa: Focus on post-translation modifications. Plant Gene 2019, 19, 100189. [CrossRef]

74. Solá, R.J.; Griebenow, K. Effects of glycosylation on the stability of protein pharmaceuticals. J. Pharm. Sci. 2009, 98, 1223-1245. [CrossRef]

75. Ahmadizadeh, M.; Chen, J.-T.; Hasanzadeh, S.; Ahmar, S.; Heidari, P. Insights into the genes involved in the ethylene biosynthesis pathway in Arabidopsis thaliana and Oryza sativa. J. Genet. Eng. Biotechnol. 2020, 18, 1-20. [CrossRef] [PubMed]

76. Rezaee, S.; Ahmadizadeh, M.; Heidari, P. Genome-wide characterization, expression profiling, and post-transcriptional study of GASA gene family. Gene Rep. 2020, 20, 100795. [CrossRef]

77. Albrecht, V.; Ritz, O.; Linder, S.; Harter, K.; Kudla, J. The NAF domain defines a novel protein-protein interaction module conserved in $\mathrm{Ca}^{2+}$-regulated kinases. EMBO J. 2001, 20, 1051-1063. [CrossRef]

78. Wu, L.-B.; Holtkamp, F.; Wairich, A.; Frei, M. Potassium ion channel gene OsAKT1 affects iron translocation in rice plants exposed to iron toxicity. Front. Plant Sci. 2019, 10, 579. [CrossRef]

79. Wang, S.-M.; Zhang, J.-L.; Flowers, T.J. Low-affinity $\mathrm{Na}^{+}$uptake in the halophyte Suaeda maritima. Plant Physiol. 2007, 145, 559-571. [CrossRef]

80. Lagarde, D.; Basset, M.; Lepetit, M.; Conejero, G.; Gaymard, F.; Astruc, S.; Grignon, C. Tissue-specific expression of Arabidopsis AKT1 gene is consistent with a role in $\mathrm{K}^{+}$nutrition. Plant J. 1996, 9, 195-203. [CrossRef]

81. Ahmad, I.; Mian, A.; Maathuis, F.J.M. Overexpression of the rice AKT1 potassium channel affects potassium nutrition and rice drought tolerance. J. Exp. Bot. 2016, 67, 2689-2698. [CrossRef]

82. Wu, H.; Zhang, X.; Giraldo, J.P.; Shabala, S. It is not all about sodium: Revealing tissue specificity and signalling roles of potassium in plant responses to salt stress. Plant Soil 2018, 431,1-17. [CrossRef]

83. De Schepper, V.; De Swaef, T.; Bauweraerts, I.; Steppe, K. Phloem transport: A review of mechanisms and controls. J. Exp. Bot. 2013, 64, 4839-4850. [CrossRef]

84. Sklodowski, K.; Riedelsberger, J.; Raddatz, N.; Riadi, G.; Caballero, J.; Chérel, I.; Schulze, W.; Graf, A.; Dreyer, I. The receptor-like pseudokinase MRH1 interacts with the voltage-gated potassium channel AKT2. Sci. Rep. 2017, 7, 44611. [CrossRef]

85. Schmidt, R.; Mieulet, D.; Hubberten, H.-M.; Obata, T.; Hoefgen, R.; Fernie, A.R.; Fisahn, J.; San Segundo, B.; Guiderdoni, E.; Schippers, J.H.M. SALT-RESPONSIVE ERF1 regulates reactive oxygen species-dependent signaling during the initial response to salt stress in rice. Plant Cell 2013, 25, 2115-2131. [CrossRef] [PubMed] 